\title{
In vitro determination of the lipophilic and hydrophilic antioxidant capacity of unroasted coffee bean extracts and their synergistic and antagonistic effects.
}

\author{
M.A. Prieto $^{1 *}$ and J.A. Vázquez ${ }^{1}$ \\ ${ }^{1}$ Grupo de Reciclado y Valorización de Materiales Residuales (REVAL), \\ Instituto de Investigacións Mariñas (IIM-CSIC) \\ r/ Eduardo Cabello, 6. Vigo-36208. Galicia - Spain \\ *Corresponding author E-mail: michaelumangelum@gmail.com
}

\begin{abstract}
The yield extraction, basic compositional analysis, individual antioxidant capacity and synergistic/antagonistic antioxidant interactions of unroasted coffee bean extracts with different degree of polarity from different locations and species were studied and compared. The beans were extracted with hexane followed by methanol to obtain lipophilic and hydrophilic extracts, respectively. Furthermore, an autoclave extraction was conducted as a simple representative approach to obtain an antioxidant rich powder for industrial application. The antioxidant capacity of all extracts and their synergistic/antagonistic responses were determined by using different but complementary well-known kinetic methods of $\beta$-carotene and crocin bleaching assays, which are representative of lipidic and hydrophilic oxidation processes. The results of this study indicated that the yield distribution and antioxidant capacity of the hydrophilic extract were much greater than the lipophilic ones, but similar to the industrial approach. The potential equivalent capacity of the industrial approach indicated that raw coffee beans possess a high content of antioxidants, offering an alternative source of nutraceuticals as well as preservatives in food formulations. Finally, statistically consistent synergistic and antagonistic values were found between the extracted coffee residues and some commercial antioxidants of well-known degree of polarity. Interestingly, it was found that the extracted residues with an equivalent degree of polarity act similar to the additive mode of interaction between single chemical entities, and as an independent interaction mode when their degree of polarity varies. The results if transferable to more realistic food matrices in the food industry, may guide the development and evaluation of food products and processes, underlying different phenomena that may affect the quality of products.
\end{abstract}

Key words: dose-response analysis; coffee antioxidant extracts; synergy and antagonism; mechanisms of interaction; antioxidant interaction; $\beta$-carotene and crocin bleaching assay 
Chemical compounds studied in this article: Linoleic acid (CID 5280450); $\beta$-Carotene (CID 5280489); Crocin (CID 5281233); butyl-hydroxyanisole (CID 24667); propyl 3,4,5trihydroxybenzoate (CID 4947); butyl-hydroxytoluene (CID 15570435); 6-ethoxy-2,2,4trimethyl-1,2-dihydroquinoline (CID 3293); 6-hydroxy-2,5,7,8-tetramethylchroman-2carboxylic acid (CID 40634); (2R)-2,5,7,8-tetramethyl-2-[(4R,8R)-(4,8,12-trimethyltridecyl)]-6chromanol (CID 14985); and (5R)-[(1S)-1,2-dihydroxyethyl]-3,4-dihydroxyfuran-2(5H)-one (CID 54670067). 


\section{INTRODUCTION}

Chronic diseases, such as cancer, atherosclerosis, diabetes, and neurogenerative pathologies are associated with oxidative stress due to the modifications caused by reactive oxygen and nitrogen species to body-target molecules (lipids, proteins and DNA) (Aruoma, 1999; Chatterjee, Poduval, Tilak, \& Devasagayam, 2005; Gutteridge \& Halliwell, 2010). Protection against these chronic diseases is associated with the regular intake of exogenous antioxidants from dietary sources such as cereals, fruits, oils, spices, vegetables and beverages (Carlsen et al., 2010; Lu, Yuan, Zeng, \& Chen, 2011; Pérez-Jiménez et al., 2008). These sources are also the main raw material to extract compounds that are useful as alternative preservatives, functional foods and nutraceuticals.

In this respect, only few studies are available to consider the raw materials of beverages, and in particular the unroasted coffee beans, as source of alternative compounds (Madhava Naidu, Sulochanamma, Sampathu, \& Srinivas, 2008; Ramalakshmi, Rahath Kubra, \& Jagan Mohan Rao, 2008). Although the antioxidant capacity $(A C)$ of roasted coffee beans is mainly attributed to the original antioxidants present in unroasted coffee beans (Borrelli, Visconti, Mennella, Anese, \& Fogliano, 2002; Ludwig et al., 2012), the brewing also contributes to enhance $A C$ (Castelluccio et al., 1995). When studying the $A C$ of coffee, most reports have focused on roasted coffee beans, a product that depends on delicate factors such as the choice of brewing technique and conditions (Daglia et al., 2000; Petracco, 2001; Terpinc, Bezjak, \& Abramovič, 2009). Recently, more works have studied the changes of $A C$ from unroasted to roasted coffee beans, optimizing the brewing conditions to obtain an antioxidant rich beverage (Madhava Naidu et al., 2008). Therefore, more details are available about the $A C$ of unroasted coffee beans from different country-climate locations and plant origins. In addition, the coffee industry, a global sector which ranks second behind the petroleum industry in terms of dollars traded, produces an excess of supply over demand which in the last three decades, has led to the reduction of prices and waste of resources. Thus, the development of value added products from unroasted coffee beans is important to help to counteract this tendency. The possibility of extraction of compounds with antioxidant properties from unroasted coffee beans may revalorize and expand the coffee market beyond the beverage one, into the food and pharmaceutical industry. 
When determining the $A C$ of samples, the analysis generally does not follow any mechanistic consideration, but rather attempts to minimize problems with respect to variability of results (Frankel \& Finley, 2008; Frankel \& Meyer, 2000). In this regard, some antioxidants $(A)$ are hydrophilic (ascorbic acid), while others are clearly lipophilic (vitamin E). Each of them have their own function in the organism, acting at different locations, but working in collaboration. To our knowledge, only a few articles have addressed the hydrophilic (H) and lipophilic (L) contribution. In addition, the synergistic and antagonistic interactions of two (or more) antioxidants, despite their importance, are only studied from simplistic views (Jia, Zhou, Yang, Wu, \& Liu, 1998; Marinova, Toneva, \& Yanishlieva, 2008; Yang et al., 2009), rather than generalizing the classical approaches (Berenbaum, 1985a, 1985b; Bliss, 1937, 1939; Greco, Bravo, \& Parsons, 1995; Loewe \& Muischnek, 1926).

In this work, firstly, we extracted the $\mathrm{H}$ and $\mathrm{L}$ antioxidant fractions of unroasted coffee beans from five different country-climate locations using a traditional chemical method from the common consumed coffee varieties (Robusta and Arabica). A simple industrial antioxidant extraction approach was also conducted. Extraction yields and basic compositional analysis were compared. Then, we applied the concentration-time response methods of $\beta$-carotene and crocin bleaching (Prieto, Rodríguez-Amado, Vázquez, \& Murado, 2012; Prieto, Vázquez, \& Murado, 2014) which are appropriate methods for lipophilic and hydrophilic matrices, respectively to provide useful complementary information regarding the study of complex natural extracts containing components with a variable degree of polarity (Prieto, Murado, Vazquez, Anders, \& Curran, 2013). Finally, we determined and quantified the synergistic or antagonistic interactions between the extracted fractions and several pairs of antioxidants of a well-known degree of polarity, using a previously developed methodological procedure (Prieto, Murado, \& Vázquez, 2013).

\section{MATERIAL AND METHODS}

\subsection{Compound extraction and preservation of coffee extracts}

A set of five unroasted coffee beans, free of additives (especially the antioxidant ones), were collected, cleaned, vacuum-packed and sent to a Spanish local manufacturer (Cafés Campinas S. Paulo). Beans were harvested in 2013 at different country locations from two different varieties: (C1) Coffea arabica from Australia; (C2) Coffea arabica from Nicaragua; (C3) Coffea 
canephora robusta, caracolillo selection, from Cameroon; (C4) Coffea arabica from Guatemala; and (C5) Coffea canephora robusta from Vietnam. Then, the coffee bean samples (500 g each) were weighed, ground, sieved using a mesh size $(<0.5 \mu \mathrm{m})$ and packed in low density poly ethylene pouches and preserved at $4-6{ }^{\circ} \mathrm{C}$ for further analysis.

The powder was extracted first with hexane and the residue obtained was then extracted with methanol in order to separate chemically the lipophilic and hydrophilic antioxidants (Jang \& Xu, 2009), respectively. Additionally, as a process that is more suitable for industrial purposes, the grounded fine powder was extracted in aqueous environment in autoclave (Almajano, Carbó, Delgado, \& Gordon, 2007; Perva-Uzunalić et al., 2006). In Figure 1, a scheme of the performed antioxidant extraction procedure is presented and in the following sub-sections described briefly.

\subsubsection{Extraction of lipophilic and hydrophilic antioxidants}

A Shoxlet system was used as a continuous method to extract antioxidant compounds with different degree of polarity (Yu, Haley, \& Perret, 2002). For each sample, a pre-weighted cellulose extraction tube $(33 \times 100 \mathrm{~mm})$ was filled with $40 \mathrm{~g}$ of fine powder sample, and transferred into a Shoxlet extractor. For the extraction of the L fraction, hexane $(250 \mathrm{~mL})$ was added and placed at the boiling point of the solvent for $12 \mathrm{~h}$ (in which 4 complete extractions were accomplished per h). Then, the extracted material was filtered through Whatman glass microfiber filters (GF/D first and GF/F after) and placed in an evaporator to remove solvent. The residue of the hexane-extracted material was re-suspended in water, lyophilized and preserved in a translucent tube at $-20^{\circ} \mathrm{C}$. The dried extract in the cellulose tube was weighed to measure its $\mathrm{L}$ extraction yield and then used for the subsequent methanol extraction. The procedure of the hydrophilic fraction was the same as the previous one, except methanol was used as the extraction solvent $(250 \mathrm{~mL})$ and the temperature of the water bath was $90^{\circ} \mathrm{C}$. The $\mathrm{H}$ and $\mathrm{L}$ residues extracted are named as $H R$ and LR, respectively.

\subsubsection{Autoclave extraction of water-soluble antioxidants. Industrial approach}

Four consecutive autoclave extractions with $100 \mathrm{~mL}$ of distilled water at $105^{\circ} \mathrm{C}$ for 60 min were applied to $10 \mathrm{~g}$ of each sample. The extracted material was centrifuged several times and the supernatant was filtered through Whatman glass microfibre filters (GF/D and GF/F), lyophilized 
and preserved at $-20^{\circ} \mathrm{C}$ (Almajano, Carbó, Delgado, \& Gordon, 2007; Perva-Uzunalić et al., 2006). The resulting aqueous residue is named as AR.

All extractions were performed in duplicate and the results of the HR, LR and AR extraction percentages are presented in Table 1. All analytical methods and antioxidant capacity determination were performed in the following days after the extraction.

\subsection{Basic analytical methods}

Dry solids $(D S)$ and ashes $(C Z)$ were conducted following the common procedures reported by Mortensen et al. (1989). Total sugar (TS) was measured using the phenol-sulfuric method (Dubois, Gilles, Hamilton, Rebers, \& Smith, 1956) and reducing sugars $(R S)$ by the dinitrosalicylic acid method (DNS) according to Bernfeld (1951), both with glucose:mannose (0.6:0.4). Protein (PRT) was quantified by the determination of total nitrogen (x 6.25) using the Kjeldahl spectrophotometer method developed by Havilah et al. (1977). Determination of total phenolic $(T P)$ content in coffee extracts was reached using the Folin-Ciocalteu reagent according to the modified method of Singleton \& Rossi (1965) using gallic acid as standard. All reagents and chemicals used were purchased from Sigma S.A. (St. Louis, MO, USA).

One $\mathrm{g}$ of sieved coffee beans was used for $D S$ and $C Z$ determination. Hundred $\mathrm{mg}$ of sieved coffee beans, HR, LR and AR were dissolved in $100 \mathrm{~mL}$ of Mili-Q water and the content of TS, $R S, P R T$ and $T P$ was determined. All tests were performed in triplicate and the results are presented in Table 1.

\subsection{Lipophilic and hydrophilic antioxidants assays: equipment, reagents and reaction conditions of $\beta$-carotene and crocin bleaching methods}

The $\beta$-carotene method ( $\beta \mathrm{CM})$ (Marco, 1968) and crocin method $(\mathrm{CM})$ (Bors, Michel, \& Saran, 1984) are two of the most common assays for the $A C$ evaluation that shares analytical similarities: 


\subsubsection{Equipment and reagents}

Equipment: Multiskan spectrum microplate photometer using polypropylene plates with 96 wells.

Antioxidants: butyl-hydroxyanisole (BHA); propyl 3,4,5-trihydroxybenzoate (Propyl gallate; PG); butyl-hydroxytoluene (BHT); 6-ethoxy-2,2,4-trimethyl-1,2-dihydroquinoline (Ethoxyquin; ETO); 6-hydroxy-2,5,7,8-tetramethylchroman-2-carboxylic acid (Trolox; TRO); (2R)-2,5,7,8tetramethyl-2-[(4R,8R)-(4,8,12-trimethyltridecyl)]-6-chromanol ( $\alpha$-tocopherol; TOC); and (5R)[(1S)-1,2-dihydroxyethyl]-3,4-dihydroxyfuran-2(5H)-one (Ascorbic acid; AA).

Other compounds: Bovine serum albumin (BSA, $66.5 \mathrm{kDa}$ ) as a protein concentration standard.

All reagents and chemicals were purchased from Sigma S.A. (St. Louis, MO, USA).

\subsubsection{Reaction conditions}

$\beta C M$ conditions (Prieto et al., 2012): Two $\mathrm{mg}$ of $\beta \mathrm{C}$ (1 $\mu \mathrm{M}$ in the final reaction), $0.25 \mathrm{~mL}$ of linoleic acid and $2 \mathrm{~g}$ of Tween-40 were dissolved in $20 \mathrm{~mL}$ of chloroform, vigorously mixed and the chloroform is evaporated $\left(45^{\circ} \mathrm{C} / \sim 15 \mathrm{~min}\right)$. To the resulting oily residue were added $300 \mathrm{~mL}$ of buffered Mili-Q water $(100 \mathrm{mM}$ Briton, $\mathrm{pH}=6.5)$ at $45^{\circ} \mathrm{C}$. The absorbance at $470 \mathrm{~nm}$ of the reagent prepared is $\sim 1.40$.

$\mathrm{CM}$ conditions (Prieto et al., 2014): Four $\mathrm{mg}$ of $\mathrm{Cr}(100 \mu \mathrm{M}$ in the final reaction) and $75 \mathrm{mg}$ AAPH (7.68 mM in the final reaction) are dissolved in $30 \mathrm{~mL}$ of a $100 \mathrm{mM}$ Briton buffer, $\mathrm{pH}=5.5$, in Mili-Q water. The absorbance at $450 \mathrm{~nm}$ of the reagent prepared is thus $\sim 1.40$.

\subsection{Determination of the antioxidant capacity and the potential equivalent activity}

The concentration ranges used for each extracted material (AR, LR and HR) of all coffee samples for the CM $300 \mu \mathrm{g}$ in the final reaction volume of $300 \mu \mathrm{L}$ (equivalently $1 \mathrm{~g} / \mathrm{L}$ ) and for the $\beta C$ M $75 \mu \mathrm{g}$ (equivalently $0.25 \mathrm{~g} / \mathrm{L}$ ). Regarding the commercial antioxidant compounds used for comparative purposes 30 and $1 \mu \mathrm{g}$ were used for the $\mathrm{CM}$ and $\beta \mathrm{CM}$, respectively.

\subsubsection{Procedure}


The procedure is performed by adding $50 \mu \mathrm{L}$ of sample and $250 \mu \mathrm{L}$ of reagent into the wells $(350 \mu \mathrm{L})$ of a microplate reader of 96 units. The microplate-reader is programmed at intervals of 3, 5 and 10 minutes (initiation, propagation and asymptotic phase), during a period of 200 minutes (total of 30 measures). The antioxidant standards and samples are analyzed kinetically for eight different doses previously ranged. All standards and samples are dissolved in water:ethanol $(9: 1)$.

\subsubsection{Quantification}

The area under the curve $(A U C)$ computed by any numerical integration method such as the trapezoidal rule, proved to be a highly robust criterion, able to summarize in a single and direct value the global feature of any kinetic profile. Then, the $A U C$ responses of a dose-response of an antioxidant is standardize in relation to $A U C$ obtained for the control which leads to the formulation of the relative area units or the substrate protected $(\bar{P})$, as defined similarly by other authors (Dávalos, 2004; Huang, Ou, Hampsch-Woodill, Flanagan, \& Prior, 2002; Naguib, 2000) for antioxidant responses:

$$
\bar{P}(A)=S_{0}\left(\frac{A U C_{C}-A U C_{A}}{A U C_{C}}\right)
$$

where $A U C_{C}$ and $A U C_{A}$ are the area units corresponding to the kinetic profiles found in the absence (control, $C$ ) and presence of an antioxidant concentration $A$, respectively, and $S_{0}$ is the initial substrate in the reaction (for the $\mathrm{CM}$, the substrate is equivalent to $100 \mu \mathrm{M}$ of $\mathrm{Cr}$ and for the $\beta \mathrm{CM}$ to $1 \mu \mathrm{M}$ of $\beta \mathrm{C}$.). The relationship in Eq. (1) establishes that $A U C_{C}$ (control) is also the maximum response achievable, consequently the values obtained are also standardized. Thus, the $\bar{P}$ value, which increases with the concentration and the power of the antioxidant $(A)$, is equivalent to the subtracted protected $(\mu \mathrm{M}$ of crocin $(\mathrm{Cr})$ or $\beta$-carotene $(\beta C)$ ). The variation of $\bar{P}$ as function of any agent can be described satisfactorily using the Weibull cumulative distribution function (Weibull \& Sweden, 1951), thus the effect of increasing concentrations of an antioxidant $(A)$ can be described in general terms as follows: 
$\bar{P}(A)=K\left\{1-\exp \left[-\ln 2(A / m)^{a}\right]\right\} \quad$ briefly; $\quad \bar{P}=W(A ; K, m, a)$

where $K$ is the specific antioxidant asymptotic value of the response, $m$ is the concentration producing the half-maximal response and $a$ is a shape parameter related to the slope that can produce potential profiles $(a<1)$, first order kinetic ones $(a=1)$ and a variety of sigmoidal profiles $(a>1)$.

\subsubsection{Comparison criteria for ranking the $A C$ and potential equivalent capacity determination}

Two meaningful ways were considered to rank the $A C$ : (1) It consists of plotting the specific $\bar{P}$ variations given by Eq. (2) as a function of the agent concentration. It provides an efficient way to determine the equivalent potential capacity of samples graphically allowing the visualization of the agent-specific dynamics; and (2) It is based on the combinatory information provided by the numerical values of the parameters $K$ and $m$ of Eq. (2). The parameter $m$ of Eq. (2) provides directly the classical $I C_{50}(\mu \mathrm{M}$ of $A$ ), which will effectively summarize all effects (time and dose) of the response, providing the key information $r$ needed to achieve a very specific response $(50 \%)$. The lower the value of $m$ is the more powerful the antioxidant would be. The parameter $K$ shows the maximum specific capability of the agent to protect the substrate $(\mu \mathrm{M}$ of $\mathrm{S})$, and as higher the value of $K$ is the more powerful the protective capabilities of the antioxidant would be. The information provided by the combination of both values represents a robust tool to compare and rank the activities of different antioxidant agents based on the parametric estimations time-dose response.

Although the graphical and numerical criteria rank the responses effectively in a time and dose form, only the numerical criteria was used to compute the potential equivalent capacity. The equivalence of each sample extract from all the coffee beans tested is computed versus common standard antioxidants by relating their parametric estimations of $K$ and $m$. The effectiveness of the coffee bean extracts versus other common antioxidants is provided by: (1) the parameter $K$ in terms of its maximum protective capabilities (in $\mu \mathrm{M} \bar{P}$ by the commercial antioxidant $/ \mu \mathrm{M} \bar{P}$ of agent tested); and (2) the parameter $m$ in terms of concentrations needed to achieve the $50 \%$ of the maximum protective effect (in $\mu \mathrm{g}$ commercial antioxidant $/ \mu \mathrm{g}$ of agent tested). Such equivalents facilitate the selection of appropriate concentrations of natural products to replace commercial antioxidants. 


\subsection{Determination of the synergistic and antagonistic effects}

In previous reports, we have developed explicit mathematical tools (Murado \& Prieto, 2013) and a methodological procedure to identify and quantify the effects of two antioxidants (Prieto, Murado \& Vázquez, 2013) that are briefly described next:

\subsubsection{Procedure}

Microplate assays were carried out by combining $8 \times 8$ arrays of two antioxidant mixtures at equally increasing concentrations, which were freshly prepared in water:ethanol (9:1). The maximum final concentration of each $A$ was $3 / 2$ of the half-life extension (parameter $m$ in Eq. (2)) identified for the individual responses. Thus, $25 \mu 1$ of each antioxidant solution was added to each well containing $250 \mu \mathrm{l}$ of the preheated reagent $\left(\mathrm{CM}: 37^{\circ} \mathrm{C}\right.$ and $\beta \mathrm{CM}$ : $\left.45^{\circ} \mathrm{C}\right)$. The apparatus was programmed for $200 \mathrm{~min}(450 \mathrm{~nm}$ for the $\mathrm{CM}$ and $470 \mathrm{~nm}$ for the $\beta C M)$, with agitation at 660 cycles/min ( $1 \mathrm{~mm}$ amplitude), which was only interrupted for readings at $3 \mathrm{~min}$ intervals. The $64 \bar{P}$ concentration combinations values obtained which summarize the individual response of the 67 independent kinetic measures, are used for identification and quantification of the interactive effects.

\subsubsection{Identification of the mode of interaction}

For the determination of the presence or absence of interactive effects of two well defined agents, two classical modes of interaction are conventional considered in the dose-response field, the independent action (IA) (Bliss, 1939) and the concentration addition (CA) (Berenbaum, 1985a; 1985b).

\section{(a) Independent action (IA)}

The basic model (null interaction or absence of interactive effects) is directly obtained by the following equation:

$$
\bar{P}\left(A_{1}, A_{2}\right)=1-\left[1-W\left(A_{1} ; K_{1}, m_{1}, a_{1}\right)\right]\left[1-W\left(A_{2} ; K_{2}, m_{2}, a_{2}\right)\right]
$$


When interactions are present, an $A$ modifies the parameters of the response to the other changing the response of Weibull's equation as function of the effect of another variable, which can be achieved by multiplying $K$ and $m$ parameters by the following hyperbolic perturbation term:

$v_{\theta i}=\left(1+b_{\theta i} A_{j}\right) /\left(1+c_{\theta i} A_{j}\right) ; \quad(\mathrm{i} \neq \mathrm{j})$

where the subscript $i$ identifies the $A$ perturbed by the $A$ noted with $j, v_{\theta \mathrm{i}}$ is the factor that multiplies the $\theta$ parameter ( $K$ or $m$ ) of the response to $A_{\mathrm{i}}$, with fitting coefficients $b_{\theta \mathrm{i}}$ and $c_{\theta \mathrm{i}}$.

Additionally, it was established that, if this independence is altered by any global cooperative or competitive effect the coefficient $s$ becomes greater or lesser than 1 depending on the predominance of competitive or cooperative effects, respectively. Thus, a generalized IA model, in its most complex form, can be written as follows:

$\bar{P}\left(A_{1}, A_{2}\right)=W\left(A_{1} ; K_{1} v_{k 1}, m_{1} v_{m 1}, a_{1}\right)+W\left(A_{2} ; K_{2} v_{k 2}, m_{2} v_{m 2}, a_{2}\right)\left[1-s \times W\left(A_{1} ; K_{1} v_{k 1}, m_{1} v_{m 1}, a_{1}\right)\right](5)$

\section{(b) Concentration addition (CA)}

The response to a mixed dose of two agents can be postulated as the response of two fictitious "mixed" doses of the same agent in the absence of interactive effects (null interaction), as follows:

$\bar{P}\left(A_{1}, A_{2}\right)=W\left[\left(A_{1}+A_{2}\right) ; K, m, a\right]$

Different possible perturbations can be postulated: interactions modifying the $A$ power, introducing a factor, $p$, to one of the doses $(p<1)$, if the affected antioxidant is the most powerful; interactions modifying the effective dose; and interactions modifying the sigmoidal parameters with the hyperbolic term as previously defined. The general model for $C A$ in its more complex form is defined as follows: 


$$
\bar{P}\left(A_{1}, A_{2}\right)=W\left[\left(p A_{1} v_{A 1}+A_{2} v_{A 2}\right) ; K v_{k 1} v_{k 2}, m v_{m 1} v_{m 2}, a\right]
$$

Eq. (5) and (7) include all the possible theoretical interactions, but much simpler situations are normally found.

\subsubsection{Quantification of the interactive effects}

An index that summarizes the complex possible effects above described is to compute the percentage relative unit of volume $(R U V)$ between the volume of the surface produced by the null interaction $\left(S V_{N I}\right)$ and the volume of the surface with interactions $\left(S V_{I}\right)$ as follows:

$$
R U V=\frac{S V_{I}-S V_{N I}}{S V_{I}} \times 100 \text {; being } S V=h_{i} h_{j} \sum_{i=0}^{n} \sum_{j=0}^{m} f\left(A_{i} A_{j}\right) \phi_{i, j}
$$

in which $A_{\mathrm{i}}$ and $A_{\mathrm{j}}$ are the dependent variables that represent the $n$ and $m$ concentration of both antioxidants, $h_{\mathrm{i}}$ and $h_{\mathrm{j}}$ are the concentration interval sets and $\Phi_{\mathrm{i}, \mathrm{j}}$ is the product of the nested composite trapezoidal rule coefficients. Therefore, positive and negative values of $R U V$ describe the predominantly synergistic and antagonistic interaction effects between the antioxidants over the study range. This index summarizes the effect produced, but changes proportional as the concentration ranges change. However, we believe that such a value can serve as a guiding value, which at least is more informative than providing proportional number of arrows up and down.

\subsection{Numerical methods}

Simulated and experimental results were adjusted to the proposed models by non-linear least squares methods (quasi-Newton), using Solver complement in Excel. Parametric estimations were performed by incorporating the 'SolverAid' macro (Prikler, 2009) for estimating the confidence intervals. Model consistency student's $t$ and Fisher's $F$ tests, with $\alpha=0.05$ in both cases were used. An automatic stepwise regression method was programmed in excel for the analysis of responses, in order to test all possible parameter combinations. The following steps 
were applied routinely: (1) fitting the sigmoidal parameters from the individual responses (without interactions), using Eq. (3) and Eq. (6) for the $I A$ and $C A$ hypothesis, respectively; (2) using the estimates as the starting values for assaying all possible parameter combinations of the Eq. (5) (IA, 9 parameters and 511 combinations) and Eq. (7) (CA, 13 parameters and 8.191 combinations); (3) rejecting those options that lead at least to a none statistically significant coefficient; and (4) selecting the most remarkable solutions, which are automatically ranked with several model selection criteria (Prieto, Murado \& Vázquez, 2013).

\section{RESULTS AND DISCUSSION}

\subsection{Extraction yields and composition analysis of coffee samples}

Table 1 lists the main composition analysis, yields of extracted fractions (HR, LR and AR) and composition analysis from unroasted coffee beans from five different country-climate locations of the most common coffee varieties (Robusta and Arabica). The following results are derived:

(a) In general, slightly differences between the compositional analyses of all coffee samples tested were found. All coffee bean samples displayed similar values of humidity $(\sim 8 \%), C Z$ residue ( $\sim 4 \%), T S(\sim 71 \%)$ and $T P(\sim 39 \%)$. With regard to $R S$ and $P R T$ composition, two groups were identified, independently of variety and climate location: for $R S \sim 19 \%$ (C5, C4 and $\mathrm{C} 2$ ) and $~ 14 \%(\mathrm{C} 3$ and $\mathrm{C} 1)$, while for $P R T \sim 17 \%(\mathrm{C} 5, \mathrm{C} 4, \mathrm{C} 3$, and C1) and 8\% (C2).

(b) Results regarding the compositional analysis of the extracted fractions (HR, LR and AR), maintain the above relations in general.

(c) The yields of the extracted fractions are: LR $\sim 5 \%$, in which $\mathrm{C} 5$ shows the lowest extracted yield and $\mathrm{C} 4$ the highest; $\mathrm{HR} \sim 18 \%$, in which $\mathrm{C} 1$ shows the lowest extracted yield and $\mathrm{C} 4$ the highest; and AR 24\%.

(d) For HR and LR, the coffee sample C4 (Coffea arabica, from Guatemala) showed the highest yields with $24 \%$ and $7 \%$, respectively. This pattern is also confirmed in the AR fraction $(26 \%)$.

\subsection{Antioxidant analysis of coffee bean samples}

Many plant extracts exhibit efficient antioxidant properties due their phytoconstituents, such as phenolics and carotenoids. To evaluate the antioxidant capacities of plant extracts, numerous in vitro methods have been developed (ORAC, TEAC, $\beta C M, C M$, TRAP and FRAP). The 
advantages and disadvantages of these methods have been fully discussed in several reviews (Frankel \& Meyer, 2000; Jiménez-Escrig, Jiménez-Jiménez, Sánchez-Moreno, \& Saura-Calixto, 2000). Methods differ in the used radical, $\mathrm{pH}$, reagents, quantification procedure to evaluate the $A C$. Meaningful comparison of the results obtained by different methods is practically impossible due to the variability in experimental conditions. However, it is also unfeasible to test compounds for each of the possible applicable real systems. Thus, an intermediate position must be found. In order to reduce these objections, in this study, we have selected the response models of $\beta \mathrm{CM}$ and $\mathrm{CM}$ because: (1) their protocols are fairly optimized at present; (2) they provide a micro-system model for the $\mathrm{L}$ and $\mathrm{H}$ oxidation processes, respectively, providing useful complementary information in the study of complex natural extracts containing components with a variable degree of polarity; and (3) they are accurate, reproducible and with low experimental error. In addition, their reactions share analytical similarities. The $\beta \mathrm{C}$ is an $\mathrm{L}$ oxidizable substrate that can join the system of lipid micelles in which the oxidation reaction is accomplished. The method is especially sensitive to oxidation modifying agents in a lipidic environment, and it produces a very low response to $\mathrm{H}$ antioxidants, even powerful ones. Complementarily, the carotenoid substrate of $\mathrm{Cr}$ is an $\mathrm{H}$ oxidizable substrate and $\mathrm{L}$ antioxidants produce very low responses in the reaction system. Therefore, for the in vitro AC evaluation, we believe those reactions reduce the variability and allow providing meaningful comparisons.

\subsubsection{Comparisons of the hydrophilic and lipophilic antioxidant capacity of $H R, L R$ and $A R$ coffee extractions}

Ramalakshmi et al., (2008) found that phenolic compounds are extracted in increasing amounts in relation to the solvent polarity. In this study, two of the classical solvents with opposite degree of polarity were used to isolate the $\mathrm{L}$ and $\mathrm{H}$ antioxidant fractions from the green coffee beans. The aqueous residue (AR) from the autoclave extraction was used as an alternative for a simple application at industrial scale to obtain compounds with antioxidant properties.

Figure 2 shows the antioxidant capacity for the AR, HR and LR extracts, evaluated in dose-time frame by the $\beta \mathrm{CM}$ and $\mathrm{CM}$. In general, none of the bleaching kinetics of the tested compounds promoted the system oxidation (pro-oxidant character). Beyond quantitative differences, all the coffee extracts promote the $A C$ in both $\mathrm{L}$ and $\mathrm{H}$ environments, apart from the $\mathrm{LR}$ extract in the $\mathrm{H}$ reaction of the $\mathrm{CM}$. The same pattern is not found when the HR extracts are tested in the $\mathrm{L}$ reaction of $\beta C M$ because at lower rates than $L$ antioxidants the $H$ antioxidants are still able to protect the lipidic oxidation of linoleic acid on the surroundings of the micro-micelles. Table 2 
displays the numeric results corresponding to the fittings to Eq. (2) of the standardized area values $(\bar{P})$ of the kinetics of $\beta \mathrm{CM}$ and $\mathrm{CM}$ bleaching reactions of all extracts from all coffee samples. The statistical analysis, parameter assessment and model prediction uncertainties provided by the 'SolverStat' and 'SolverAid' were satisfactory. The adjusted coefficients of determination $R_{a d j}^{2}$ of all fitting solutions were always greater than 0.96 , with a majority of fittings above 0.99. Figure A1 (appendix section) presents the corresponding graphical fitting results which were found to be consistent always (p-values $<0.001$ from Fisher's $F$ test). When two comparative criteria, graphical or numerical, are used, the responses are summarized effectively facilitating the $A C$ ranking process.

The graphical representation is the most intuitive and visual form to analyze and compare the non-linear $A C$ dose-response rigorously. Figure 3 (part A) shows behavior profile of the coffee as function of its concentration. The responses are compared with common commercial antioxidants. In order to simplify, for the hydrophilic (Figure 3 part A1) and lipophilic (Figure 3 part A2) assessed environments, the dose-responses of coffee extracts and the commercial antioxidants are expressed in $\mu \mathrm{g}$ of the compound used in the final volume of the reaction (300 $\mu \mathrm{L})$. In general terms, the concentration ranges needed to achieve similar protective capabilities, were much higher in the hydrophilic environment $(250 \mu \mathrm{g}$ of coffee extracts) than in the lipophilic ones $(75 \mu \mathrm{g})$. However, when compared against the graphical plots of commercial antioxidants, the $A C$ was higher in $\mathrm{H}$ environments ( 10 times less effective than commercial) than in $\mathrm{L}$ ones ( 75 times). The $A C$ differences of the coffee samples are narrow. The HR and $\mathrm{AR}$ in $\mathrm{H}$ environment display very similar pattern behaviors, while in the L environment the AR shows higher $A C$ capabilities than the HR. Regarding the effect of the LR in L environment, in identical concentration ranges, lower effective responses than in the HR and AR are found. In relation to the effective $A C$ of the commercial antioxidants used as example, the ETX showed the greatest protective effects in both $\mathrm{L}$ and $\mathrm{H}$ reactions.

The assessment criteria based on the parametric estimations of $K$ and $m$ obtained from Eq. (2) represent a meaningful tool free of intuitive interpretations. Figure 3 (B1 and B2) display the combinatory information of both parameters for each of the extracted residues analyzed in $\mathrm{H}$ and $\mathrm{L}$ antioxidant reactions. In both reactions, the parameter $K$ of the AR and HR extracts for all coffee samples verifies that the capabilities to counteract the oxidation of the $\mathrm{Cr}$ and $\beta \mathrm{C}$ substrates are $\sim 60-80 \%$. Those values are greater than some values obtained for the standard antioxidants. In the case of the LR, as described previously, much lower effects are found ( 20- 
$40 \%$ ). When the analyses are based on the $m$ parameter, the HR and AR extracts show that in the $\mathrm{H}$ reactions $\sim 110-130 \mu \mathrm{g}$ are needed, while $\sim 8-11 \mu \mathrm{g}$ are needed in the $\mathrm{L}$ environment provided by $\beta \mathrm{CM}$.

The ranking effects of the $A C$ of the extracts of the coffee bean samples are summarized in decreasing order as follows:

(a) For the $\mathrm{AR}$ in the $\mathrm{H}$ reaction the order was $\mathrm{C} 5>\mathrm{C} 4>\mathrm{C} 3>\mathrm{C} 2>\mathrm{C} 1$, while in the $\mathrm{L}$ reaction $\mathrm{C} 5>\mathrm{C} 2>\mathrm{C} 4>\mathrm{C} 3>\mathrm{C} 1$.

(b) For the HR in the $\mathrm{H}$ reaction the order was $\mathrm{C} 5>\mathrm{C} 2>\mathrm{C} 3>\mathrm{C} 1>\mathrm{C} 4$, while in the $\mathrm{L}$ reaction $\mathrm{C} 5>\mathrm{C} 4>\mathrm{C} 2>\mathrm{C} 1>\mathrm{C} 3$.

(c) For the $\mathrm{LR}$ in the $\mathrm{L}$ reaction the order was $\mathrm{C} 4>\mathrm{C} 3>\mathrm{C} 2>\mathrm{C} 1>\mathrm{C} 5$. In general, $\mathrm{C} 5$ and $\mathrm{C} 4$ presented higher $A C$ values than other coffee samples.

Slightly significant differences between the coffee samples are shown, without clear correlations between the plant varieties, climate origins or compositional analysis of the coffee samples or extracts and final $A C$ ranking. Between plant varieties, our results agree with the data of Daglia et. al., (2000), but in a much lower scale. In relation to different climate locations, the data of Parras et al., (2007) proved consistent $A C$ variances, that were not found in our results. Although a relationship between $A C$ and total polyphenol, another compositional compound, plant variety or climate location would not be rare, its absence is not surprising either, since many chemical families can include particular compounds with very different specific powers and capabilities that can act with different degrees of effects in those different environments.

\subsubsection{Determination of the potential equivalent capacity of coffee extracts}

Commercial antioxidants, such as BHA and BHT, are used repeatedly as additives for preventing and reducing oxidative changes in food. Despite the potential risk associated with their use, these antioxidants and others still the most effective solution for many food industrial uses worldwide (Hocman, 1988; Ito, Hirose, Fukushima, \& Tsuda, 1986; Moch, 1986). In this regard, researchers have searched many traditional plants for naturally occurring compounds with $A C$. Several studies have demonstrated the disease preventative and health-promoting effects against oxidative stress of herbs, spices, cereals, and legumes and explored them as potential sources of antioxidants for food preservation (Yusri, Chan, Iqbal, \& Ismail, 2012). 
In vitro assays provide relevant information about the antioxidant effect, comparison among extracts and selection of best antioxidant candidates. We have previously ranked the $A C$, thus, in this section the potential equivalent capacity of the coffee residues extracted for different standard antioxidants were quantified. The equivalences would provide relevant information on the appropriate concentrations of natural products to replace commercial antioxidants.

The equivalence is computed in terms of the numerical parameters $K$ and $m$ of Eq. (2) as described in the material and methods section. Figure A2 (appendix section) shows the specific potential equivalence of each coffee fractionated residues tested regarding to five common commercial antioxidants for each of the $\mathrm{H}$ and $\mathrm{L}$ reactions (for the CM: AA, ETX, PG, TBHQ, TRO and for the $\beta C M$ : BHA, ETX, BHT, TOC, PG). Since the results involved the numerical values of the parameters $K$ and $m$ of Eq. (2), the main patterns and rankings previously found remain identical, and the information provided is only relevant to each specific commercial antioxidant. The differences noticed between the coffee samples from different plant varieties and climate origins in terms of compositional analysis and $A C$ are narrow. For simplicity reasons, the parametric equivalences to commercial antioxidants of all extracted samples are averaged and displayed in Figure 4. Therefore, from this analysis the following general conclusions are derived:

(a) In general, the differences were much higher in $\mathrm{L}$ than in $\mathrm{H}$ environment. Also, the equivalences found between the AR and HR are narrow, with significant higher values in the AR than in the HR. In terms of the protective capabilities ( $K$ parameter), similar results between the extracts and the commercial antioxidants were found. However, in terms of doses needed ( $m$ parameter), the coffee samples are much less effective than the commercial antioxidants.

(b) More specifically, in terms of the parameter $K$, in the H reaction the AR and HR have similar protective capacities than AA, PG and TRO, $\sim 2$ times higher than TBHQ and $\sim 2$ times lesser than ETX. For the L reaction, the AR and HR have similar protective capacities than BHA, $\sim 2$ times higher than TOC and $~ 1.5$ times lesser than ETX, BHT and PG. For the LR in the $\mathrm{L}$ reaction all the commercial antioxidants are between 2-3 times more effective.

(c) In terms of the parameter $m$, in the $\mathrm{H}$ reaction the AR and HR need $\sim 20$ times the concentration of AA, PG and TRO, $\sim 5$ times more than TBHQ and $\sim 110$ times more than ETX. For the L reaction, the AR and HR need $\sim 3$ times the concentration of PG, 40 times 
more than BHT and TOC, $\sim 200$ times more than BHA and $\sim 1000$ times more than ETX. For the LR in the L reaction, all the commercial antioxidants are between 200-3000 times more effective.

The equivalent potential capacity of coffee extracts reported in this study is only valid for in vitro responses. The effectiveness of antioxidants depends on chemical, physical, and environmental factors (such as free radical and oxidant sources, $\mathrm{pH}$, reagents, ionic strength, etc). These factors vary in food and biological matrixes, and thus, to properly account the antioxidant effectiveness must be determined for each individual system. Such an approach is time-consuming and often expensive or impractical. Accordingly, in the last decade, a large number of fast response assays have been developed for the in vitro estimations of AC. Although the in vitro methods to test AC have increasingly been made more complex, they do not take into account important factors affecting effectiveness of antioxidants. From the obtained results by different methods, meaningful extrapolations to real systems are practically impossible due to the variability in experimental conditions. Knowing the limitations, we have used two in vitro systems that recreate the $\mathrm{L}$ and $\mathrm{H}$ environments to evaluate the antioxidant activity of different polarity extracts from several unroasted coffee beans. Thus, if any of these natural extracts were required to replace commercial antioxidants, the in vitro responses only serve as guiding values of the real responses that may be found in in vivo assessments.

\subsubsection{Autoclave extraction as a simple industrial approach}

Other authors (Bekedam, Roos, Schols, Van Boekel, \& Smit, 2008b; Delgado-Andrade, RufinHenares, \& Francisco, 2005) have also found that coffee extract obtained with pure solvents (such as methanol or hexane) showed significantly lower results of antioxidant activity in comparison with pure water extracts. The higher extractions yields and $A C$ results for the AR compared to the HR or LR could be due to several physico-chemical reasons which have been discussed already (Bekedam, Roos, Schols, Van Boekel, \& Smit, 2008a). In conclusion, it seems that the AR extracts have a higher antioxidant capapcity than the HR or LR. Our results agree with those observed by other authors who found the highest antioxidant yields in those extracts obtained from water from roasted coffee residues.

In addition, from a practical point of view, the use of an AR extract is more convenient than the use of alcoholic extracts, both in the laboratory and in the food industry in order to obtain 
antioxidant spent coffee extracts and to use them as a natural food preservatives. In conclusion, the extraction of AR by an autoclave treatment appears to be an excellent technological process, both for analysis and extension to industrial scale due to its simplicity, low cost and high efficiency in extracting antioxidants. In addition, the autoclave treatment could act as an alternative to obtain compounds with antioxidant properties in order to revalorize and expand the market of coffee beans beyond the beverage one.

\subsection{Synergistic and antagonistic effects between coffee bean extracts and commercial antioxidants with different degrees of polarity}

Based on results previously published (Bruun-Jensena \& Skovgaardb, 1994; Cuvelier \& Berset, 2003; Yang et al., 2009), when more than one antioxidant is present in a controlled environment, the final $A C$ found, in many occasions it is higher of lower than expected. The two classical hypotheses, the IA and CA, are used to try to define the unexpected interactive results derived from the combination of more than one antioxidant. In addition, to the synergistic/antagonistic effects between antioxidants, other substances such as protein compounds (e.g., BSA and casein) have been repeatedly mentioned due to their capability to enhance the $A C$ of antioxidants. Therefore, in this work based on a previous methodology (Prieto, Murado, \& Vázquez, 2013), we have extended the $A C$ analysis by defining and quantifying the interactive effects between: (1) the different degree of polarity of the coffee extracted residues; (2) BSA; and (3) some commercial antioxidants of a well-known degree of polarity.

The interactive effects of the extracts from different coffee samples were tested between them and versus the other compounds. Because only slightly differences were found between different coffe samples in the $\mathrm{H}$ and $\mathrm{L}$ antioxidant methods, for simplicity reasons, the coffee sample $\mathrm{C} 4$ was selected to be the representative sample for the determination and quantification of synergy/antagonism. The reasons to select the $\mathrm{C} 4$ extracts and not others was because, as an average, ranked as the highest in terms of yield extracts and second regarding the AC.

Figure 5 and Figure 6 show the matrix combination of 21 binary agents for each of the $\mathrm{H}$ and $\mathrm{L}$ reaction. Each pair of agents displays 64 concentration combinations in terms of $\bar{P}$ values. Each $\bar{P}$ value summarizes, in standardized area units, the individual response of 67 independent kinetic measures. All binary agent responses are subjected to the automatic stepwise regression analysis described in the numerical methods section, which provides the information regarding 
the mode of interaction by applying Eq. (5) and (7), the $I A$ and $C A$ hypothesis, respectively. The modes of interaction, parametric estimations, confidence intervals and statistical information of best fitting results derived, for each of the binary combinations tested, are presented in Table A1 and Table A2 (appendix section). Once the mode of interaction is identified, the quantification of the interactive effects is determined in terms of $R U V$ by means of Eq. (8). Table 3 displays the $R U V$ obtained for the binary combination between the coffee extracted residues, BSA and commercial antioxidants for both $\mathrm{H}$ and $\mathrm{L}$ methods.

Eq. (5) and (7) (IA and CA respectively) define hypothesis for the combination of similar or dissimilar individual chemical entities, and its use with extracts formed by mixture of agents are at least controversial. To our knowledge, no tools or hypothesis have been developed for testing mixtures of compounds. Thus, we treat the extracted residues as a mixture of compounds with an equivalent degree of polarity. Therefore, we are testing the collective degree of polarity of the compounds mixture in the extracts, rather than well-defined chemical entities. In any case, the responses to the binary joint interaction of pure antioxidants (such as BHT, ETX, TRO) and the mixture of antioxidant compounds from different chemical entities (extracted residues RA, RH and RL), but equivalent degree of polarity, produced consistent results in all cases. The adjusted coefficients of determination $R_{a d j}^{2}$ (Table A1 and Table A2) of all fitting solutions were always greater than 0.97 , with a wide majority of the fittings superior at 0.99 . The response effect of the combination mixtures in terms of $R U V(\%)$, as described by Eq. (8), are display in Table 3. Therefore, the following conclusions can be derived:

(a) In terms of the mode of interaction, in general, highly correlated results with the degree of polarity of the compounds were found. When two lipophilic antioxidants were mixed, independent of the environmental reaction $(\mathrm{L}$ or $\mathrm{H})$, the mode of interaction was $\mathrm{CA}$, and when the mixed compounds had different polarity affinities was IA. However, there are some exceptions, such as TRO vs AR in the CM, in which as a function of their polarity affinities one could expect a CA response, but it shows a better fitting results under the assumption of IA hypothesis. Probably the reasons under this non-correlated behavior are behind the aqueous extraction itself, in which lipophilic antioxidants may have also been extracted, acting at different points of the $\mathrm{H}$ reaction (IA mode). This possibility may be confirm by looking at the results of $\mathrm{AR}$ and $\mathrm{AH}$ versus all other compounds, in which always their interactive effects showed similar results as exception of the cases BHT vs AR $(\mathrm{BCM})$ and $\mathrm{AA} v s \mathrm{AR}(\mathrm{CM})$. In those cases, their interactive effects were higher than when 
HR was used. This information also shows that some other different compounds are extracted that caused some other type the interactions increasing the synergistic effects.

(b) In terms of the type of interactions (synergistic/antagonistic/null interaction). Only three cases were found with clear antagonistic responses, the ETX vs TRO and AR vs AH in the H reaction and RL vs ETX in the L reaction. Only the case of ETX vs BSA in the H reaction did not produce significant lower or higher responses than expected (null interaction). However, there were few cases that their synergistic effects were lower than $2 \%$, in the L reaction (RH vs RA; BSA vs RH; RL vs BHT) and in the $\mathrm{H}$ reaction (RH vs RA), in which aslo null interaction hypothesis could be admitted. In all the others binary combinations, statistically significant synergistic effects were found.

(c) In terms of the quantification of the interactive synergistic responses, in general, the $\mathrm{H}$ interactions were stronger than the $\mathrm{L}$ ones. In $\mathrm{H}$ environment, the responses that showed synergistic interactions can be grouped as follows: (1) Synergistic effects $<20 \%$ (TRO vs HR; TRO vs AR; TRO vs BSA; ETX vs HR; ETX vs AR; AA vs HR; AA vs TRO; AA vs ETX); (2) Synergistic effects between 20-30 \% (AA vs AR); and (3) Synergistic effects > 30 $\%$ (BSA vs HR; BSA vs AR; BSA vs AA). In L environment, the responses that showed synergistic interactions can be grouped as follows: (1) Synergistic effects $<10 \%$ (AR vs HR; LR vs HR; LR vs AR; BSA vs HR; BSA vs AR; BHT vs HR; BHT vs LR; BHT vs ETX); (2) Synergistic effects between 10-20\% (BSA vs LR; BHT vs BSA); and (3) Synergistic effects $>20 \%$ (ETX $v s$ HR; ETX $v s$ BSA).

(d) Another interesting aspect of results described is the high positive interactions found when BSA is used versus almost all other compounds, such as ETX vs BSA (46\%) in the L reaction and AA vs BSA (56\%) in the $\mathrm{H}$ reaction. As exceptional cases $\mathrm{RH} v s \mathrm{RA}$ and BSA vs $\mathrm{RH}$ in the $\mathrm{L}$ reaction shows a nearly null interaction, but when the same mixtures are used in the $\mathrm{H}$ reaction, high powerful interactions are seen.

A part from exceptional cases, if the behavior described in (a) is confirmed in other areas of study, may show some interesting concepts to the field of the interactive effects of compounds, indicating that the polarity of the compounds may be highly correlated with the mode of interaction, independently of the surrounding environment. Regarding the high positive interactions described in (c), the authors lack of a knowledge to explain the reasons why in the presence of very high concentrations of BSA, some compounds, independently of the hypotheses that you use, show a clear unexpected increase in their protective interaction in both $\mathrm{L}$ and $\mathrm{H}$ reactions. 


\section{CONCLUSIONS}

The extracted HR, LR and AR from unroasted coffee beans from five different country-climate locations of the most common coffee varieties (Robusta and Arabica) were analyzed and discussed. The specific $\mathrm{H}$ and $\mathrm{L}$ antioxidant character of the coffee samples selected and their extracted fractions were analyzed and compared in detail, based on the responses of the $\beta C$ and $\mathrm{Cr}$ dose-time methods which are appropriate for $\mathrm{L}$ and $\mathrm{H}$ matrices, respectively. Those methods provided useful complementary information regarding the study of complex natural extracts containing components with a variable degree of polarity. All coffee bean samples promoted the antioxidant capacity in both lipophilic and hydrophilic environments, but higher $A C$ were found in the hydrophilic environments. Results indicated that green coffee possess compounds with potential applications as nutraceuticals and as preservatives in food formulations. In addition, a simple industrial extraction approach, by an autoclave treatment (aqueous residue), was proposed as an alternative to improve supply over demand and to obtain compounds with antioxidant properties in order to revalorize and expand the market of coffee beans beyond the beverage one. Finally, we determined and quantified the synergistic and antagonistic interactions between the extracted fractions and several pairs of antioxidants of a well-known degree of polarity, some new concepts useful for other fields of study were found.

The robustness of the antioxidant methods applied, combined with the summarizing attributes of the standardized area values and the accuracy of the fitting solutions by the mathematical tools applied, provided comprehensive and global solution. Therefore, we believe that the results here presented allow to perform in vitro comparisons providing ranks of their $A C$, potential equivalences and relevant information regarding its interactive effects in a much more easily and reliable way than usual.

\section{AKNOWLEDGEMENT}

The authors wish to thank Ministerio de Ciencia e Innovación (project CTM2010-18411, cofinanced with FEDER funds by European Union) for financial support. Miguel Angel Prieto Lage was awarded one grant from the JAE predoctoral program co-financed by the CSIC and European Social Fund (ESF). The authors want to express their gratitude to Mss. Araceli 
Menduiña Santomé for her valuable technical work. We also want to thank to the local manufacturer (CAFÉS CAMPINAS S. PAULO) who provided freely the coffee samples. 


\section{TABLE CAPTIONS}

Table 1: Percentage of dry solids $(D S)$ and ashes $(C Z)$ of the coffee types obtained (C1-C5). Yield percentage of the extraction procedure (HR, LR and AR) for each type of coffee types assessed. Compositional analysis of the extracted powder (TS, RS, $P R T$ and $T P$ ), in all cases the percentage is referred to the total w/w of the tea extracted material (\% EM).

Table 2: Numeric results corresponding to the kinetics of the bleaching reactions of $\mathrm{CM}$ and $\beta C M$ ( $L$ and $H$ reactions, respectively) of coffee extracts (HR, LR and AR) and commercial antioxidants fitted to the Eq. (2). No results were found when the liphophilic residue was tested in the hydrophilic reaction $(\mathrm{CM})$.

Table 3: Effect of the combination of 42 different pairs of antioxidants for each reaction. Those in which one antioxidant is combined with itself are used simply as controls. For each case the $R U V(\%)$ is computed as described by Eq. (8). Note the differences in the scale in concentration ranges.

\section{APPENDIX TABLE CAPTIONS}

Table A1: Parametric values of the joint interaction of six different antioxidants in the crocin oxidation reaction. The null interaction and synergy hypotheses are compared under the independent action and addition concentration suppositions, by fitting the experimental results to the (5) and (7) generalized models. In all the presented results the parameters estimations are significant.

Table A2: Parametric values of the joint interaction of six different antioxidants in the crocin oxidation reaction. The null interaction and synergy hypotheses are compared under the independent action and addition concentration suppositions, by fitting the experimental results to the (5) and (7) generalized models. In all the presented results the parameters estimations are significant.

\section{FIGURE CAPTIONS}


Figure 1: Scheme of the antioxidant extraction procedure performed.

Figure 2: Antioxidant activity of coffee extracts (aqueous, hydrophilic and lipophilic residue) in both $\mathrm{CM}$ and $\beta \mathrm{CM}$ reactions (lipophilic and hydrophilic media respectively); Control series and seven dilutions $(\bigcirc: 1 / 7, \boldsymbol{\Delta}: 2 / 7, \triangle: 3 / 7, \mathbf{\square}: 4 / 7, \square: 5 / 7, \diamond: 6 / 7, \diamond: 7 / 7)$ were included in each case. The concentrations range tested for all extracts are $0-(0.1)-0.7 \mathrm{~g} / \mathrm{L}$ in final solution of the reaction. No results were found when the lipophilic residue was tested in the hydrophilic reaction $(\mathrm{CM})$.

Figure 3: Graphical and numerical comparative criteria for the $A C$ ranking process of the five different varieties of coffee extracts (AR, LR and HR) against some commercial antioxidants by means of $\beta \mathrm{CM}$ and CM. A: Plotting the specific $\bar{P}$ variations given by Eq. (2) as a function of the agent concentration. B: Numerical criteria calculated with the $K$ and $m$ parameters obtained in Eq. (2). Note concentration scales for commercial antioxidants are in $\mu$ g. No results were found when the lipophilic residue was tested in the hydrophilic reaction (CM). Parametric estimates and confidence intervals are shown in Table 2.

Figure 4: Global potential AC equivalence of each the fractionated residues (AR, HR and LR) from the averaged results of the coffee samples tested (C1-C5) against five common commercial antioxidants for each of the $\mathrm{H}$ and L reactions, the CM (AA, ETX, PG, TBHQ and TRO) and the $\beta C M$ (BHA, ETX, BHT, TOC and PG). The equivalence is computed in terms of the numerical parameters $K$ and $m$ of Eq. (2). The graphs display the times less effective that the coffee samples are regarding the commercial antioxidant by the two different but complementary parameter values of Eq. (2). The left axis computes the times less effective of all coffee samples in terms of its maximum protective capabilities (parameter $K$ in $\mu \mathrm{M} \bar{P}$ by the commercial antioxidant $/ \mu \mathrm{M} \bar{P}$ by the corresponding coffee sample), while the right axis computes the times more effective of all coffee samples in terms of concentrations needed to achieve the $50 \%$ of the maximum protective effect (parameter $m$ in $\mu \mathrm{g}$ commercial antioxidant $/ \mu \mathrm{g}$ respective coffee extract). Readers should note the break of the right axis.

Figure 5: Matrix combination responses for the CM, which is organized as follows: a) in the diagonal it can be seem the results obtained for the controls; b) in the top part of the diagonal the surface responses for each pair antioxidant combination is presented; and c) in the bottom diagonal part the differences "scenery" between their respective null interaction form and the 
obtained response is presented. Numerical results are in Table A1 and Table 3. The reader should note that the resulting scenery of the case AA vs BSA has different $R$ axes that all other ones.

Figure 6: Matrix combination responses for the $\beta \mathrm{CM}$, which is organized as follows: a) in the diagonal it can be seem the results obtained for the controls; b) in the top part of the diagonal the surface responses for each pair antioxidant combination is presented; and c) in the bottom diagonal part the differences "scenery" between their respective null interaction form and the obtained response is presented. Numerical results are in Table A2 and Table 3. The reader should note that the resulting scenery of the case ETX $v s$ RH, ETX $v s$ RA and ETX $v s$ BSA has different $R$ axes that all other ones.

\section{APPENDIX FIGURE CAPTIONS}

Figure A1: The points correspond to the standardized area values as substrate $(\beta \mathrm{C}$ or $\mathrm{Cr})$ protected $(\bar{P})$ of the kinetics of the bleaching reactions of $\beta \mathrm{CM}$ (lipophilic) and $\mathrm{CM}$ (hydrophilic) of all extracts (AR, HR and LR) from the coffee samples (C1-C5) tested (raw kinetic data in Figure 2). The lines correspond to the fittings to Eq. (2) of the standardized area values $(\bar{P})$. Parametric estimations, confidence intervals and statistical information of each of the fittings to Eq. (2) are showed in Table 2. No results were found when the lipophilic residue was tested in the hydrophilic reaction $(\mathrm{CM})$.

Figure A2: Specific potential equivalence of each the fractionated residues (AR, HR and LR) of all coffee samples tested (C1-C5) against five common commercial antioxidants for each of the $\mathrm{H}$ and $\mathrm{L}$ reactions, the CM (AA, ETX, PG, TBHQ and TRO) and the $\beta \mathrm{CM}$ (BHA, ETX, BHT, TOC and PG). The equivalence is computed in terms of the numerical parameters $K$ and $m$ from Eq. (2). Each independent graph belongs to the computed equivalence referred to the commercial antioxidant indicated on the left side. All graphs display the times less effective that the coffee samples are regarding the commercial antioxidant by the two different but complementary parameter values of Eq. (2). The left axis computes the times less effective of all coffee samples in terms of its maximum protective capabilities (parameter $K$ in $\mu \mathrm{M} \bar{P}$ by the commercial antioxidant / $\mu \mathrm{M} \bar{P}$ by the corresponding coffee sample), while the right axis computes the times less effective of all coffee samples in terms of concentrations needed to 
achieve the $50 \%$ of the maximum protective effect (parameter $m$ in $\mu \mathrm{g}$ commercial antioxidant / $\mu \mathrm{g}$ respective coffee extract). Readers should note the break of the right axis. 


\section{REFERENCIAS}

Almajano, M. P., Carbó, R., Delgado, M. E., \& Gordon, M. H. (2007). Effect of pH on the antimicrobial activity and oxidative stability of oil-in-water emulsions containing caffeic acid. Journal of Food Science, 72(5), C258-63.

Aruoma, O. (1999). Antioxidant actions of plant foods: use of oxidative DNA damage as a tool for studying antioxidant efficacy. Free Radical Research, 30(6), 419-27.

Bekedam, E., Roos, E., Schols, H., Van Boekel, M., \& Smit, G. (2008a). Electron spin resonance (ESR) studies on the formation of roasting-induced antioxidative structures in coffee brews at different degrees of roast. Journal of Agricultural and Food Chemistry, 56(12), 4597-4604.

Bekedam, E., Roos, E., Schols, H., Van Boekel, M., \& Smit, G. (2008b). Low molecular weight melanoidins in coffee brew. Journal of Agricultural and Food Chemestry, 56(11), 40604067.

Berenbaum, M. C. (1985a). Consequences of synergy between environmental carcinogens. Environmental Research, 38(2), 310-318.

Berenbaum, M. C. (1985b). The expected effect of a combination of agents: the general solution. Journal of Theoretical Biology, 114(3), 413-31.

Bernfeld, P. (1951). Enzymes of starch degradation and synthesis. Advances in Enzymology, 12, 379-427.

Bliss, C. I. (1937). The calculation of the time-mortality curve. Annals of Applied Biology, 24, 815-824.

Bliss, C. I. (1939). The toxicity of poisons applied jointly. Annals of Applied Biology, 26(3), 585-615.

Borrelli, R. C., Visconti, A., Mennella, C., Anese, M., \& Fogliano, V. (2002). Chemical characterization and antioxidant properties of coffee melanoidins. Journal of Agricultural and Food Chemistry, 50, 6527-6533.

Bors, W., Michel, C., \& Saran, M. (1984). Inhibition of the bleaching of the carotenoid crocin a rapid test for quantifying antioxidant activity. Biochimica et Biophysica Acta, 796(3), 312319.

Bruun-Jensena, L., \& Skovgaardb, I. (1994). Antioxidant synergism between tocopherols and ascorbyl palmitate in cooked, minced turkey. Zeitschrift Für Lebensmittel-Untersuchung Und Forschung, 199(3), 210-213.

Carlsen, M. H., Halvorsen, B. L., Holte, K., Bøhn, S. K., Dragland, S., Sampson, L., et. al. The total antioxidant content of more than 3100 foods, beverages, spices, herbs and supplements used worldwide. Nutrition Journal, 9(3), 1-12. 
Castelluccio, C., Paganga, G., Melikian, N., Bolwell, G. P., Pridham, J., Sampson, J., \& RiceEvans, C. (1995). Antioxidant potential of intermediates in phenylpropanoid metabolism in higher plants. FEBS Letters, 368, 188-192.

Chatterjee, S., Poduval, T. B., Tilak, J. C., \& Devasagayam, T. P. A. (2005). A modified, economic, sensitive method for measuring total antioxidant capacities of human plasma and natural compounds using Indian saffron (Crocus sativus). Clinica Chimica Acta; International Journal of Clinical Chemistry, 352(1-2), 155-63.

Cuvelier, M. E., \& Berset, C. (2003). Antioxidant activity of phenolic compounds in 2,2'-azobis (2-amidinopropane) dihydrochloride (AAPH)-induced oxidation: Synergistic and antagonistic effects. Journal of the American Oil Chemists' Society, 80(10), 1007-1012.

Daglia, M., Papetti, A., Gregotti, C., Bertè, F., \& Gazzani, G. (2000). In vitro antioxidant and ex vivo protective activities of green and roasted coffee. Journal of Agricultural and Food Chemistry, 48, 1449-1454.

Dávalos, A. (2004). Extending applicability of the oxygen radical absorbance capacity (ORACfluorescein) assay. Journal of Agricultural and Food Chemestry, 52(1), 48-54.

Delgado-Andrade, C., Rufin-Henares, J. A., \& Francisco, J. M. (2005). Assessing the antioxidant activity of melanoidins from coffee brews by different antioxidant methods. Journal of Agricultural and Food Chemestry, 53(20), 7832-7836.

Dubois, M., Gilles, K. A., Hamilton, J. K., Rebers, P. A., \& Smith, F. (1956). Colorimetric method for determination of sugars and related substances. Analytical Chemistry, 28(3), $350-356$.

Faller, A. L. K., \& Fialho, E. (2009). The antioxidant capacity and polyphenol content of organic and conventional retail vegetables after domestic cooking. Food Research International, 42(1), 210-215.

Frankel, E. N., \& Finley, J. W. (2008). How to standardize the multiplicity of methods to evaluate natural antioxidants. Journal of Agricultural and Food Chemistry, 56(13), 4901-8.

Frankel, E. N., \& Meyer, A. S. (2000). The problems of using one-dimensional methods to evaluate multifunctional food and biological antioxidants. Journal of the Science of Food and Agriculture, 80(13), 1925-1941.

Garc1, M., Pascual-teresa, S. De, \& Santos-buelga, C. (2004). Evaluation of the antioxidant properties of fruits. Food Chemistry, 84(1), 13-18.

Greco, W. R., Bravo, G., \& Parsons, J. C. (1995). The search for synergy: a critical review from a response surface perspective. Pharmacological Reviews, 47(2), 331-385.

Gutteridge, J. M. C., \& Halliwell, B. (2010). Antioxidants: Molecules, medicines, and myths. Biochemical and Biophysical Research Communications, 393(4), 561-4.

Havilah, E. J., Wallis, D. M., Morris, R., \& Woolnough, J. A. (1977). A micro-colorimetric method for determination of ammonia in Kjeldahl digests with a manual spectrophotometer. Lab. Pract., 26, 545-547. 
Hocman, G. (1988). Chemoprevention of cancer: phenolic antioxidants (BHT, BHA). International Journal of Biochemistry, 20(7), 639-651.

Huang, D., Ou, B., Hampsch-Woodill, M., Flanagan, J., \& Prior, R. (2002). High-throughput assay of oxygen radical absorbance capacity (ORAC) using a multichannel liquid handling system coupled with a microplate fluorescence reader in 96-well format. Journal of Agricultural and Food Chemistry, 50(16), 4437-44.

Ito, N., Hirose, M., Fukushima, S., \& Tsuda, H. (1986). Studies on antioxidants: their carcinogenic and modifying effects on chemical carcinogenesis. Food and Chemical Toxicology, 24(10-11), 1071-1082.

Jang, S., \& Xu, Z. (2009). Lipophilic and hydrophilic antioxidants and their antioxidant activities in purple rice bran. Journal of Agricultural and Food Chemistry, 57(3), 858-62.

Jia, Z. S., Zhou, B., Yang, L., Wu, L. M., \& Liu, Z. L. (1998). Antioxidant synergism of tea polyphenols and tocopherol against free radical induced peroxidation of linoleic acid in solution. J. Chem. Soc., Perkin Trans. 2, 1(4), 911-916.

Jiménez-Escrig, A., Jiménez-Jiménez, I., Sánchez-Moreno, C., \& Saura-Calixto, F. (2000). Evaluation of free radical scavenging of dietary carotenoids by the stable radical 2,2diphenyl-1-picrylhydrazyl. Journal of the Science of Food and Agricultu, 80(11), 16861690.

Loewe, S., \& Muischnek, H. (1926). Über Kombinationswirkungen. Naunyn-Schmiedebergs Archiv Für Experimentelle Pathologie Und Pharmakologie, 114(5-6), 313-326.

Lu, M., Yuan, B., Zeng, M., \& Chen, J. (2011). Antioxidant capacity and major phenolic compounds of spices commonly consumed in China. Food Research International, 44(2), $530-536$.

Ludwig, I. a., Sanchez, L., Caemmerer, B., Kroh, L. W., De Peña, M. P., \& Cid, C. (2012). Extraction of coffee antioxidants: Impact of brewing time and method. Food Research International, 48(1), 57-64.

Madhava Naidu, M., Sulochanamma, G., Sampathu, S. R., \& Srinivas, P. (2008). Studies on extraction and antioxidant potential of green coffee. Food Chem., 107(1), 377-384.

Marco, G. J. (1968). A rapid method for evaluation of antioxidants. Journal of the American Oil Chemists' Society, 45(9), 594-598.

Marinova, E., Toneva, A., \& Yanishlieva, N. (2008). Synergistic antioxidant effect of [alpha]tocopherol and myricetin on the autoxidation of triacylglycerols of sunflower oil. Food Chem., 106(2), 628-633.

Moch, R. W. (1986). Pathology of BHA-and BHT-induced lesions. Food and Chemical Toxicology, 24, 1167-1169.

Mortensen, A. B., Wallin, H., Appelqvist, L. A., Everitt, G., Gref, C. G., Jacobsen, J., ... Julshamn, K. (1989). Gravimetric determination of ash in foods: NMKL collaborative study. Journal Association of Official Analytical Chemists, 72(3), 481-483. 
Murado, M. A., \& Prieto, M. A. (2013). Dose-Response Analysis in the Joint Action of Two Effectors. A New Approach to Simulation, Identification and Modelling of Some Basic Interactions. PLoS ONE, 8(4), e61391.

Naguib, Y. M. (2000). A fluorometric method for measurement of oxygen radical-scavenging activity of water-soluble antioxidants. Analytical Biochemistry, 284(1), 93-8.

Parras, P., Martínez-Tomé, M., Jiménez, A., \& Murcia, M. (2007). Antioxidant capacity of coffees of several origins brewed following three different procedures. Food Chemistry, 102(3), 582-592.

Pellegrini, N., Serafini, M., Salvatore, S., Del Rio, D., Bianchi, M., \& Brighenti, F. (2006). Total antioxidant capacity of spices, dried fruits, nuts, pulses, cereals and sweets consumed in Italy assessed by three different in vitro assays. Molecular Nutrition \& Food Research, 50, $1030-1038$.

Pérez-Jiménez, J., Arranz, S., Tabernero, M., Díaz- Rubio, M. E., Serrano, J., Goñi, I., \& SauraCalixto, F. (2008). Updated methodology to determine antioxidant capacity in plant foods, oils and beverages: Extraction, measurement and expression of results. Food Research International, 41(3), 274-285.

Perva-Uzunalić, A., Škerget, M., Knez, Ž., Weinreich, B., Otto, F., \& Grüner, S. (2006). Extraction of active ingredients from green tea (Camellia sinensis): Extraction efficiency of major catechins and caffeine. Food Chemistry, 96(4), 597-605.

Petracco, M. (2001). Technology IV: beverage preparation: brewing trends for the new millennium. R. J. Clark, \&O. G. Vitzthum(Eds.), Coffee: Recent Developments (R. J. Clar., Vol. lopments.O).

Prieto, M. A., Murado, M. A., \& Vázquez, J. A. (2013). Quantification, characterization and description of synergy and antagonism in the antioxidant response. Food Research International, (In press). doi:10.1016/j.foodres.2013.09.033

Prieto, M. A., Murado, M. A., Vazquez, J. A., Anders, Y., \& Curran, T. P. (2013). A new microplate procedure for simultaneous assessment of lipophilic and hydrophilic antioxidants and pro-oxidants, using crocin and $\beta$-carotene bleaching methods in a single combined assay: Tea extracts as a case study. Food Research International, 53(2), 836846.

Prieto, M. A., Rodríguez-Amado, I., Vázquez, J. A., \& Murado, M. A. (2012). $\beta$-Carotene assay revisited. Application to characterize and quantify antioxidant and prooxidant activities in a microplate. Journal of Agricultural and Food Chemestry, 60(36), 8983-8993.

Prikler, S. (2009). Robert de Levie: Advanced Excel for scientific data analysis, 2nd ed. Analytical and Bioanalytical Chemistry, 395(7), 1945.

Ramalakshmi, K., Rahath Kubra, I., \& Jagan Mohan Rao, L. (2008). Antioxidant potential of low-grade coffee beans. Food Research International, 41(1), 96-103. 
Singleton, V. L., \& Rossi, J. A. (1965). Colorimetry of Total Phenolics with PhosphomolybdicPhosphotungstic Acid Reagents. American Journal of Enology and Viticulture, 16(3), 144 158.

Terpinc, P., Bezjak, M., \& Abramovič, H. (2009). A kinetic model for evaluation of the antioxidant activity of several rosemary extracts. Food Chemistry, 115(2), 740-744.

Weibull, W., \& Sweden, S. (1951). A statistical distribution function of wide applicability. Journal of Applied Mechanics, 18(3), 293-297.

Yang, W.-J., Li, D.-P., Li, J.-K., Li, M.-H., Chen, Y.-L., \& Zhang, P.-Z. (2009). Synergistic antioxidant activities of eight traditional Chinese herb pairs. Biological \& Pharmaceutical Bulletin, 32(6), 1021-6.

Yu, L., Haley, S., \& Perret, J. (2002). Free radical scavenging properties of wheat extracts. Journal of Agricultural and Food Chemestry, 50(6), 1619-24. 
Table 1: Percentage of dry solids $(D S)$ and ashes $(C Z)$ of the coffee types obtained (C1-C5). Yield percentage of the extraction procedure (HR, LR and AR) for each type of coffee types assessed. Compositional analysis of the extracted powder (TS, RS, PRT and TP), in all cases the percentage is referred to the total $\mathrm{w} / \mathrm{w}$ of the tea extracted material (\% EM).

\begin{tabular}{|c|c|c|c|c|c|c|c|}
\hline \multirow{3}{*}{$\begin{array}{c}\text { Coffee } \\
\text { samples }\end{array}$} & \multicolumn{7}{|c|}{ Main compositional analysis of tea extracts } \\
\hline & $D S$ & $C Z$ & Yield & TS & RS & $P R T$ & $T P$ \\
\hline & $\%$ & $\%$ & $\%$ & $\%$ EM & $\%$ EM & $\%$ EM & $\%$ EM \\
\hline$C 1$ & 93.06 & 4.03 & - & 71.06 & 14.52 & 22.05 & 38.04 \\
\hline$C 2$ & 92.94 & 3.61 & - & 69.90 & 18.64 & 8.93 & 37.42 \\
\hline C3 & 92.70 & 3.29 & - & 72.74 & 13.45 & 17.26 & 38.94 \\
\hline C4 & 92.64 & 3.79 & - & 74.10 & 18.61 & 15.32 & 39.66 \\
\hline$C 5$ & 92.65 & 4.30 & - & 73.58 & 20.20 & 19.25 & 39.39 \\
\hline C1-HR & - & - & 15.43 & 49.89 & 11.03 & 11.49 & 17.83 \\
\hline$C 2-H R$ & - & - & 19.69 & 52.25 & 15.07 & 12.03 & 21.95 \\
\hline C3-HR & - & - & 20.98 & 71.44 & 14.29 & 13.63 & 21.92 \\
\hline C4-HR & - & - & 24.43 & 63.34 & 17.20 & 14.58 & 21.38 \\
\hline C5-HR & - & - & 18.77 & 59.61 & 17.70 & 13.73 & 29.62 \\
\hline$C 1-L R$ & - & - & 5.93 & 13.04 & 5.26 & 37.05 & 10.52 \\
\hline$C 2-L R$ & - & - & 5.96 & 11.60 & 4.23 & 22.18 & 8.45 \\
\hline$C 3-L R$ & - & - & 5.24 & 6.16 & 4.81 & 36.91 & 9.62 \\
\hline$C 4-L R$ & - & - & 7.76 & 6.54 & 3.43 & 29.16 & 6.86 \\
\hline$C 5-L R$ & - & - & 3.17 & 8.10 & 4.05 & 33.52 & 8.10 \\
\hline$C 1-A R$ & - & - & 24.83 & 63.32 & 14.00 & 21.25 & 25.94 \\
\hline$C 2-A R$ & - & - & 24.14 & 78.88 & 27.47 & 28.25 & 22.09 \\
\hline$C 3-A R$ & - & - & 23.59 & 62.57 & 27.00 & 20.99 & 23.00 \\
\hline$C 4-A R$ & - & - & 25.83 & 60.31 & 32.38 & 20.24 & 28.52 \\
\hline$C 5-A R$ & - & - & 25.12 & 63.38 & 40.70 & 21.27 & 36.64 \\
\hline
\end{tabular}

$D S$ : dry solids, $C Z$ : ashes, $T S$ : total sugars, $R S$ : reduce sugars, $P R T$ : proteins and TP: total polyphenols. HR: hydrophilic residue, LR: lipophilic residue, AR: aqueous residue. 
Table 2: Numeric results corresponding to the kinetics of the bleaching reactions of $\mathrm{CM}$ and $\beta C M$ ( $L$ and $H$ reactions, respectively) of coffee extracts (HR, LR and AR) and commercial antioxidants fitted to the Eq. (2). No results were found when the liphophilic residue was tested in the hydrophilic reaction $(\mathrm{CM})$.

\begin{tabular}{|c|c|c|c|c|}
\hline \multirow[b]{2}{*}{ SAMPLES } & \multicolumn{3}{|c|}{ FITTING PARAMETERS } & \multirow{2}{*}{$R_{a d j}^{2}$} \\
\hline & $\begin{array}{c}\boldsymbol{K} \\
(\mu g \mathrm{~S} \text { protected })\end{array}$ & $\underset{(\mu g A)}{\boldsymbol{m}}$ & $\begin{array}{l}a \\
--\end{array}$ & \\
\hline
\end{tabular}

A: $\beta C M(L I P O P H I L I C)$

\begin{tabular}{|c|c|c|c|c|}
\hline C1-HR & $0.602 \pm 0.5$ & $12.05 \pm 1.0$ & $0.85 \pm 0.9$ & 0.9999 \\
\hline$C 2-H R$ & $0.471 \pm 0.7$ & $7.87 \pm 1.6$ & $0.96 \pm 0.8$ & 0.9981 \\
\hline C3-HR & $0.669 \pm 7.1$ & $14.54 \pm 14.9$ & $0.76 \pm 8.3$ & 0.9977 \\
\hline$C 4-H R$ & $0.573 \pm 4.3$ & $10.05 \pm 9.0$ & $0.89 \pm 10.7$ & 0.9997 \\
\hline$C 5-H R$ & $0.638 \pm 1.1$ & $9.30 \pm 2.4$ & $0.79 \pm 2.5$ & 0.9968 \\
\hline$C 1-L R$ & $0.244 \pm 18.0$ & $234.56 \pm 41.5$ & $0.54 \pm 11.8$ & 0.9705 \\
\hline$C 2-L R$ & $0.487 \pm 59.1$ & $533.75 \pm 2.1$ & $0.56 \pm 37.1$ & 0.9324 \\
\hline$C 3-L R$ & $0.416 \pm 1.7$ & $173.79 \pm 0.6$ & $0.66 \pm 24.8$ & 0.9860 \\
\hline$C 4-L R$ & $0.412 \pm 25.6$ & $668.31 \pm 3.3$ & $0.63 \pm 15.2$ & 0.9855 \\
\hline$C 5-L R$ & $0.226 \pm 3.2$ & $540.93 \pm 0.2$ & $0.37 \pm 44.5$ & 0.9854 \\
\hline$C 1-A R$ & $0.695 \pm 0.3$ & $11.36 \pm 0.5$ & $0.95 \pm 0.6$ & 0.9998 \\
\hline$C 2-A R$ & $0.819 \pm 1.8$ & $11.15 \pm 3.6$ & $0.80 \pm 3.1$ & 0.9973 \\
\hline$C 3-A R$ & $0.780 \pm 1.9$ & $12.50 \pm 3.7$ & $0.86 \pm 3.4$ & 0.9884 \\
\hline$C 4-A R$ & $0.634 \pm 0.3$ & $8.31 \pm 0.8$ & $0.94 \pm 1.1$ & 0.9740 \\
\hline$C 5-A R$ & $0.790 \pm 0.3$ & $7.31 \pm 1.0$ & $0.88 \pm 1.2$ & 0.9988 \\
\hline$B H A$ & $0.776 \pm 7.6$ & $0.0511 \pm 11.5$ & $1.04 \pm 5.7$ & 0.9990 \\
\hline$E T X$ & $0.991 \pm 5.2$ & $0.0068 \pm 0.4$ & $1.50 \pm 9.8$ & 0.9983 \\
\hline BHT & $0.911 \pm 23.6$ & $0.4545 \pm 3.3$ & $1.18 \pm 1.3$ & 0.9950 \\
\hline TOC & $0.487 \pm 3.2$ & $0.1938 \pm 7.9$ & $1.32 \pm 1.1$ & 0.9939 \\
\hline$P G$ & $0.990 \pm 9.2$ & $3.5872 \pm 2.6$ & $0.50 \pm 18.4$ & 0.9965 \\
\hline \multicolumn{5}{|c|}{ B: CM (HYDROPHILIC) } \\
\hline$C 1-H R$ & $70.74 \pm 5.8$ & $168.66 \pm 2.8$ & $1.49 \pm 6.1$ & 0.9931 \\
\hline$C 2-H R$ & $65.07 \pm 4.8$ & $128.95 \pm 0.1$ & $1.51 \pm 6.7$ & 0.9951 \\
\hline C3-HR & $78.52 \pm 2.8$ & $171.46 \pm 0.9$ & $1.32 \pm 3.7$ & 0.9952 \\
\hline C4-HR & $60.57 \pm 6.2$ & $122.02 \pm 0.1$ & $1.66 \pm 9.1$ & 0.9891 \\
\hline C5-HR & $71.29 \pm 4.3$ & $130.66 \pm 0.6$ & $1.42 \pm 0.2$ & 0.9908 \\
\hline$C 1-L R$ & -- & -- & -- & -- \\
\hline$C 2-L R$ & -- & -- & -- & -- \\
\hline$C 3-L R$ & -- & -- & -- & -- \\
\hline$C 4-L R$ & -- & -- & -- & -- \\
\hline$C 5-L R$ & -- & -- & -- & -- \\
\hline$C 1-A R$ & $72.35 \pm 4.6$ & $164.71 \pm 1.4$ & $1.57 \pm 11.6$ & 0.9927 \\
\hline$C 2-A R$ & $56.83 \pm 2.7$ & $122.40 \pm 1.7$ & $2.05 \pm 4.8$ & 0.9878 \\
\hline$C 3-A R$ & $64.66 \pm 5.5$ & $141.01 \pm 1.6$ & $1.95 \pm 2.9$ & 0.9925 \\
\hline$C 4-A R$ & $59.37 \pm 3.7$ & $125.34 \pm 1.3$ & $1.97 \pm 13.5$ & 0.9915 \\
\hline$C 5-A R$ & $63.81 \pm 0.8$ & $112.78 \pm 0.2$ & $1.84 \pm 11.4$ & 0.9895 \\
\hline $\boldsymbol{A A}$ & $57.21 \pm 1.6$ & $4.96 \pm 3.1$ & $0.81 \pm 3.74$ & 0.9998 \\
\hline$E T X$ & $98.23 \pm 15.1$ & $0.78 \pm 1.4$ & $1.15 \pm 18.3$ & 0.9998 \\
\hline$P G$ & $70.56 \pm 2.9$ & $3.49 \pm 5.0$ & $0.93 \pm 15.3$ & 0.9961 \\
\hline$T B H Q$ & $35.79 \pm 1.2$ & $12.32 \pm 3.7$ & $0.90 \pm 51.3$ & 0.9999 \\
\hline$T R O$ & $78.73 \pm 0.2$ & $3.93 \pm 5.8$ & $1.20 \pm 19.2$ & 0.9992 \\
\hline
\end{tabular}

Confidence intervals for $\alpha=0.05 . R_{a d j}^{2}$ : correlation coefficient adjusted between observed and predicted values. 
Table 3: Effect of the combination of 42 different pairs of antioxidants for each reaction. Those in which one antioxidant is combined with itself are used simply as controls. For each case the $R U V(\%)$ is computed as described by Eq. (8). Note the differences in the scale in the concentration ranges.

\section{A: $\beta C M$ (LIPOPHILIC)}

\begin{tabular}{lccccccc}
\hline & \multicolumn{2}{c}{ HR } & AR & LR & BSA & ETX & BHT \\
\hline$(0-100 \mu \mathrm{g})$ & HR & $N I-C A(0.0 \%)$ & $S-C A(1.9 \%)$ & $S-I A(3 \%)$ & $S-C A(1 \%)$ & $S-I A(36.2 \%)$ & $S-I A(3 \%)$ \\
$(0-100 \mu \mathrm{g})$ & AR & - & $N I-C A(0.0 \%)$ & $S-I A(9.6 \%)$ & $S-C A(0.6 \%)$ & $S-I A(31.4 \%)$ & $S-I A(24.3 \%)$ \\
$(0-100 \mu \mathrm{g})$ & LR & - & - & $N I-C A(0.0 \%)$ & $S-I A(14.3 \%)$ & $A-A C(-13.1 \%)$ & $S-C A(1.6 \%)$ \\
$(0-3 \mathrm{mg})$ & BSA & - & - & - & $N I-C A(0.0 \%)$ & $S-I A(46.5 \%)$ & $S-I A(11.2 \%)$ \\
$(0-20 \mathrm{ng})$ & ETX & - & - & - & - & $N I-C A(0.0 \%)$ & $S-I A(5.6 \%)$ \\
$(0-1.5 \mu \mathrm{g})$ & BHT & - & - & - & - & - & $N I-C A(0.0 \%)$ \\
\hline
\end{tabular}

B: CM (HYDROPHILIC)

\begin{tabular}{lccccccc}
\hline & & HR & AR & BSA & TRO & ETX & AA \\
\hline$(0-250 \mu \mathrm{g})$ & HR & $N I-C A(0.0 \%)$ & $A-A C(-1.8 \%)$ & $S-A C(36.8 \%)$ & $S-A C(5.1 \%)$ & $S-A I(9.8 \%)$ & $S-A I(2.9 \%)$ \\
$(0-250 \mu \mathrm{g})$ & AR & - & $N I-C A(0.0 \%)$ & $S-A C(37.7 \%)$ & $S-A I(5.7 \%)$ & $S-A I(14.4 \%)$ & $S-A I(20.1 \%)$ \\
$(0-30 \mathrm{mg})$ & BSA & - & - & $N I-C A(0.0 \%)$ & $S-A C(12.2 \%)$ & $S-A C(0.3 \%)$ & $S-A I(56.8 \%)$ \\
$(0-15 \mu \mathrm{g})$ & TRO & - & - & - & $N I-C A(0.0 \%)$ & $A-A I(-6.1 \%)$ & $S-A I(7.7 \%)$ \\
$(0-3 \mu \mathrm{g})$ & ETX & - & - & - & - & $N I-C A(0.0 \%)$ & $S-A I(9.4 \%)$ \\
$(0-30 \mu \mathrm{g})$ & AA & - & - & - & - & - & $N I-C A(0.0 \%)$ \\
\hline
\end{tabular}




\section{FIGURES}

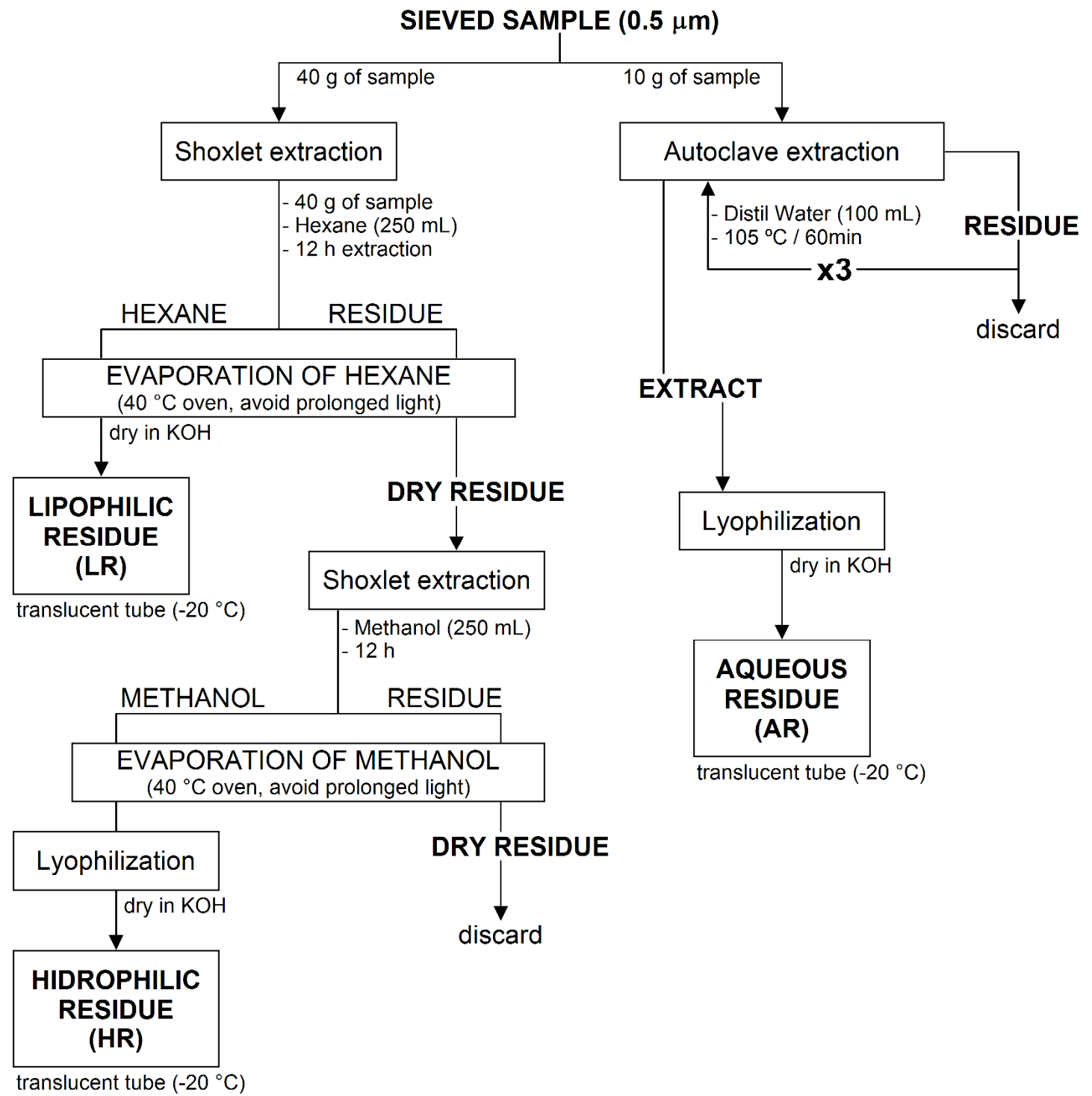

Figure 1: Scheme of the antioxidant extraction procedure performed 


\section{AQUEOUS RESIDUE

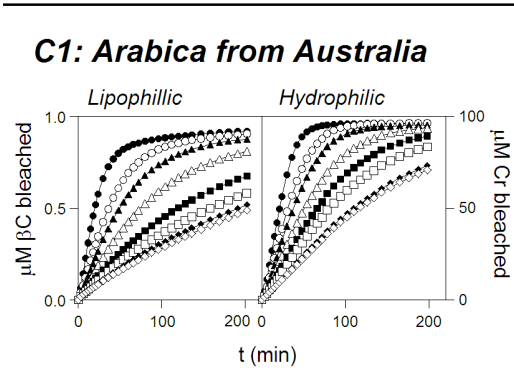

C2: Arabica from Nicaragua

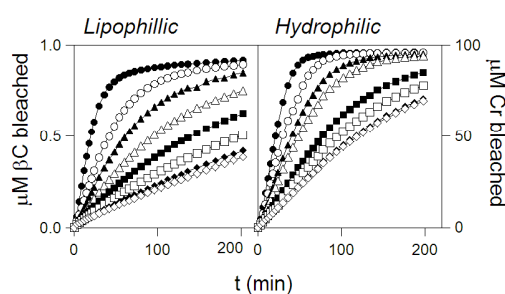

C3: Robusta from Cameroon

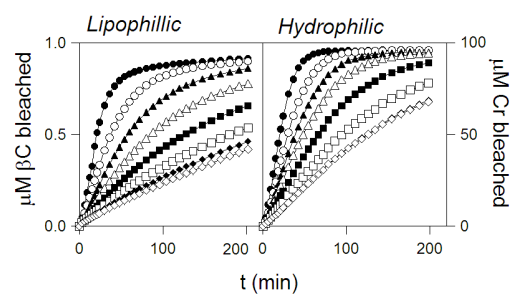

C4: Arabica from Guatemala

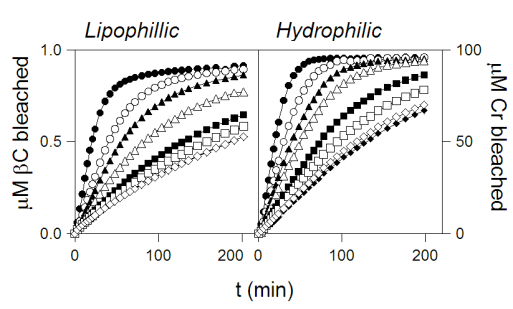

C5: Robusta from Vietnam

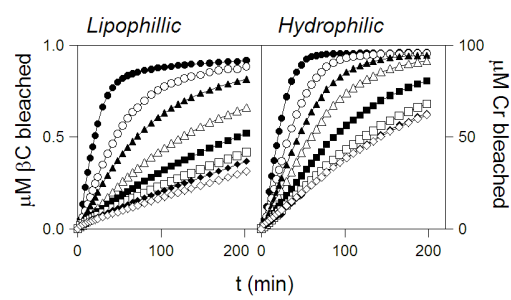

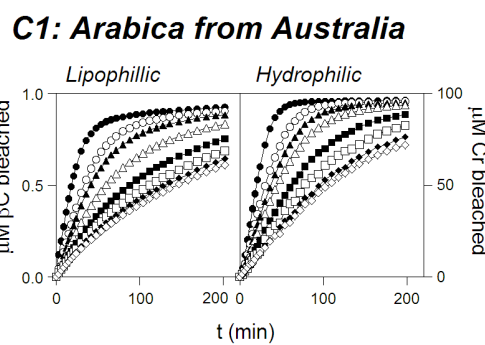

C2: Arabica from Nicaragua

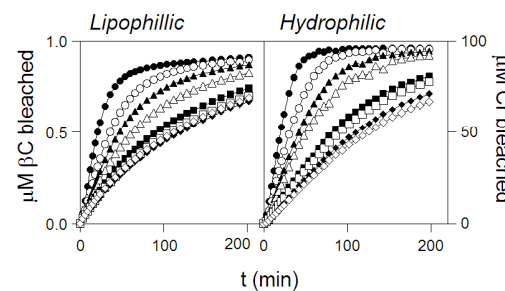

C3: Robusta from Cameroon

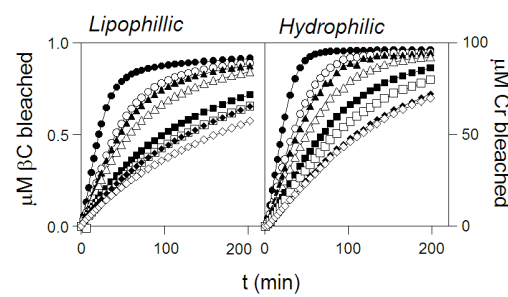

C4: Arabica from Guatemala

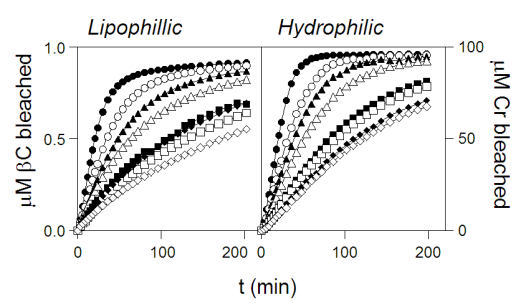

C5: Robusta from Vietnam

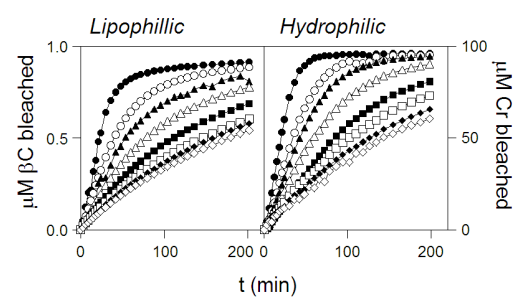

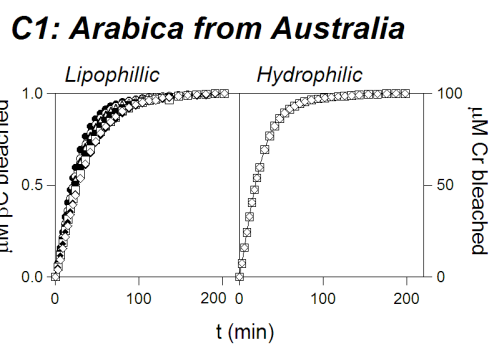

C2: Arabica from Nicaragua

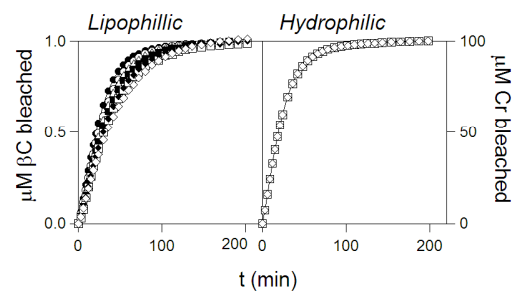

C3: Robusta from Cameroon

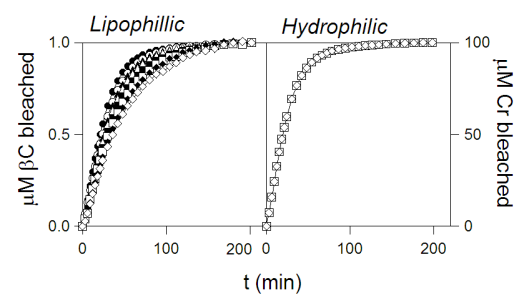

C4: Arabica from Guatemala

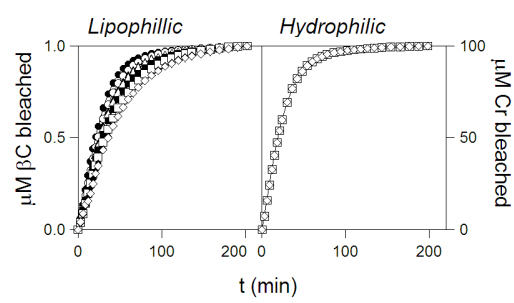

C5: Robusta from Vietnam

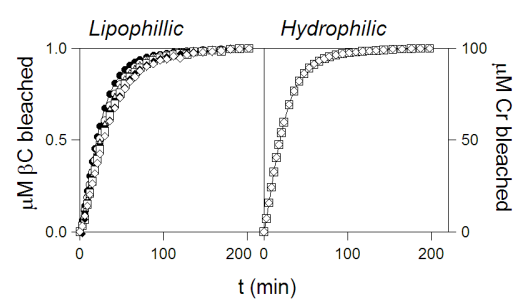

Figure 2: Antioxidant activity of coffee extracts (aqueous, hydrophilic and lipophilic residue) in both $\mathrm{CM}$ and $\beta \mathrm{CM}$ reactions (lipophilic and hydrophilic media respectively); Control series (๑) and seven dilutions $(\bigcirc: 1 / 7, \boldsymbol{\Delta}: 2 / 7, \triangle: 3 / 7, \mathbf{\square}: 4 / 7, \square: 5 / 7, \diamond: 6 / 7, \diamond: 7 / 7)$ were included in each case. The concentrations range tested for all extracts are $0-(0.1)-0.7 \mathrm{~g} / \mathrm{L}$ in final solution of the reaction. No results were found when the lipophilic residue was tested in the hydrophilic reaction $(\mathrm{CM})$. 


\section{A: GRAPHICAL CRITERIA}

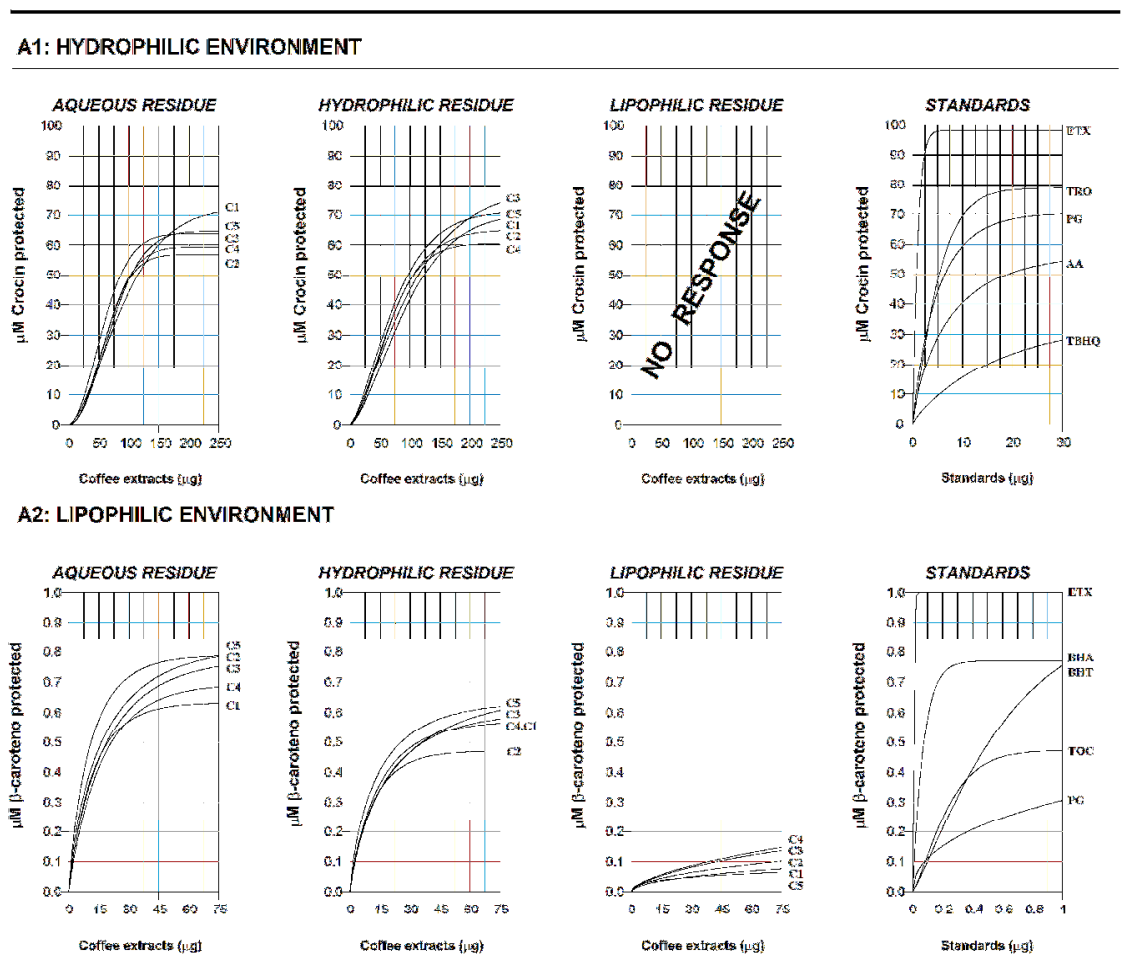

\section{B: NUMERICAL CRITERIA}

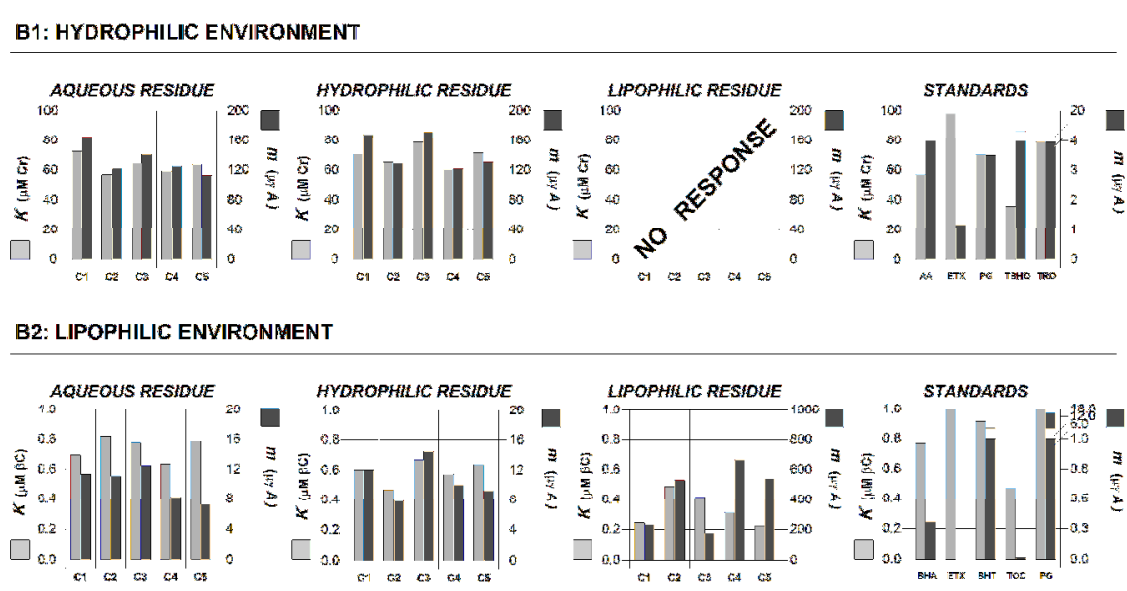

Figure 3: Graphical and numerical comparative criteria for the $A C$ ranking process of the five different varieties of coffee extracts (AR, LR and HR) against some commercial antioxidants by means of $\beta C M$ and CM. A: Plotting the specific $\bar{P}$ variations given by Eq. (2) as a function of the agent concentration. B: Numerical criteria calculated with the $K$ and $\mathrm{m}$ parameters obtained in Eq. (2). Note concentration scales for commercial antioxidants are in $\mu \mathrm{g}$. No results were found when the lipophilic residue was tested in the hydrophilic reaction (CM). Parametric estimates and confidence intervals are shown in Table 2. 


\section{A: HYDROPHILIC (CM)}

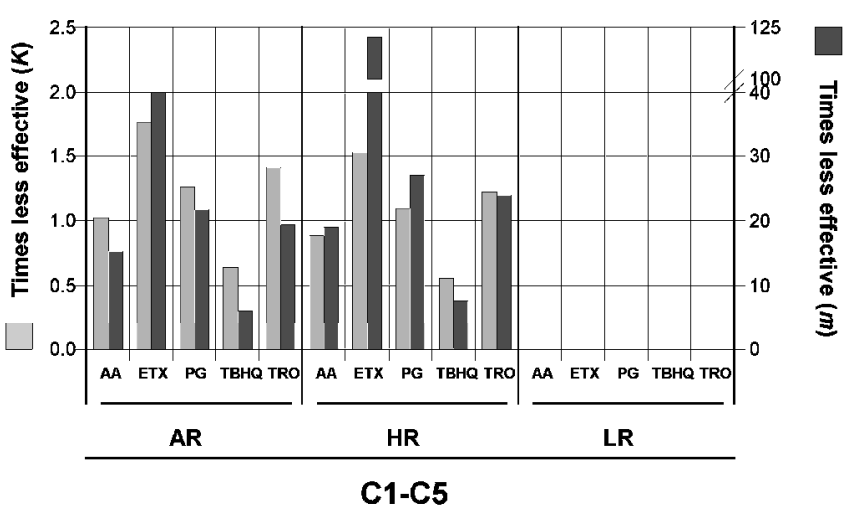

\section{B: LIPOPHILIC ( $\beta C M)$}

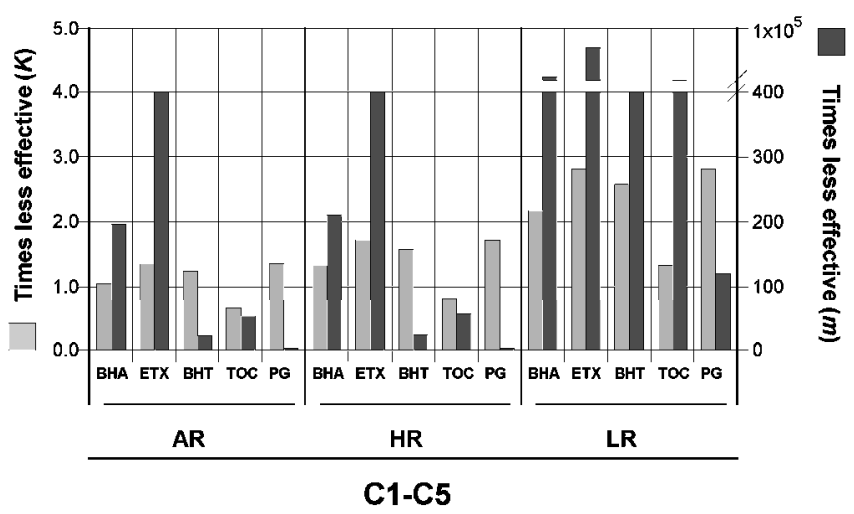

Figure 4: Global potential AC equivalence of each the fractionated residues (AR, HR and LR) from the averaged results of the coffee samples tested (C1-C5) against five common commercial antioxidants for each of the $\mathrm{H}$ and $\mathrm{L}$ reactions, the CM (AA, ETX, PG, TBHQ and TRO) and the $\beta C M$ (BHA, ETX, BHT, TOC and PG). The equivalence is computed in terms of the numerical parameters $K$ and $m$ of Eq. (2). The graphs display the times less effective that the coffee samples are regarding the commercial antioxidant by the two different but complementary parameter values of Eq. (2). The left axis computes the times less effective of all coffee samples in terms of its maximum protective capabilities (parameter $K$ in $\mu \mathrm{M} \bar{P}$ by the commercial antioxidant $/ \mu \mathrm{M} \bar{P}$ by the corresponding coffee sample), while the right axis computes the times more effective of all coffee samples in terms of concentrations needed to achieve the $50 \%$ of the maximum protective effect (parameter $m$ in $\mu \mathrm{g}$ commercial antioxidant / $\mu \mathrm{g}$ respective coffee extract). Readers should note the break of the right axis. 


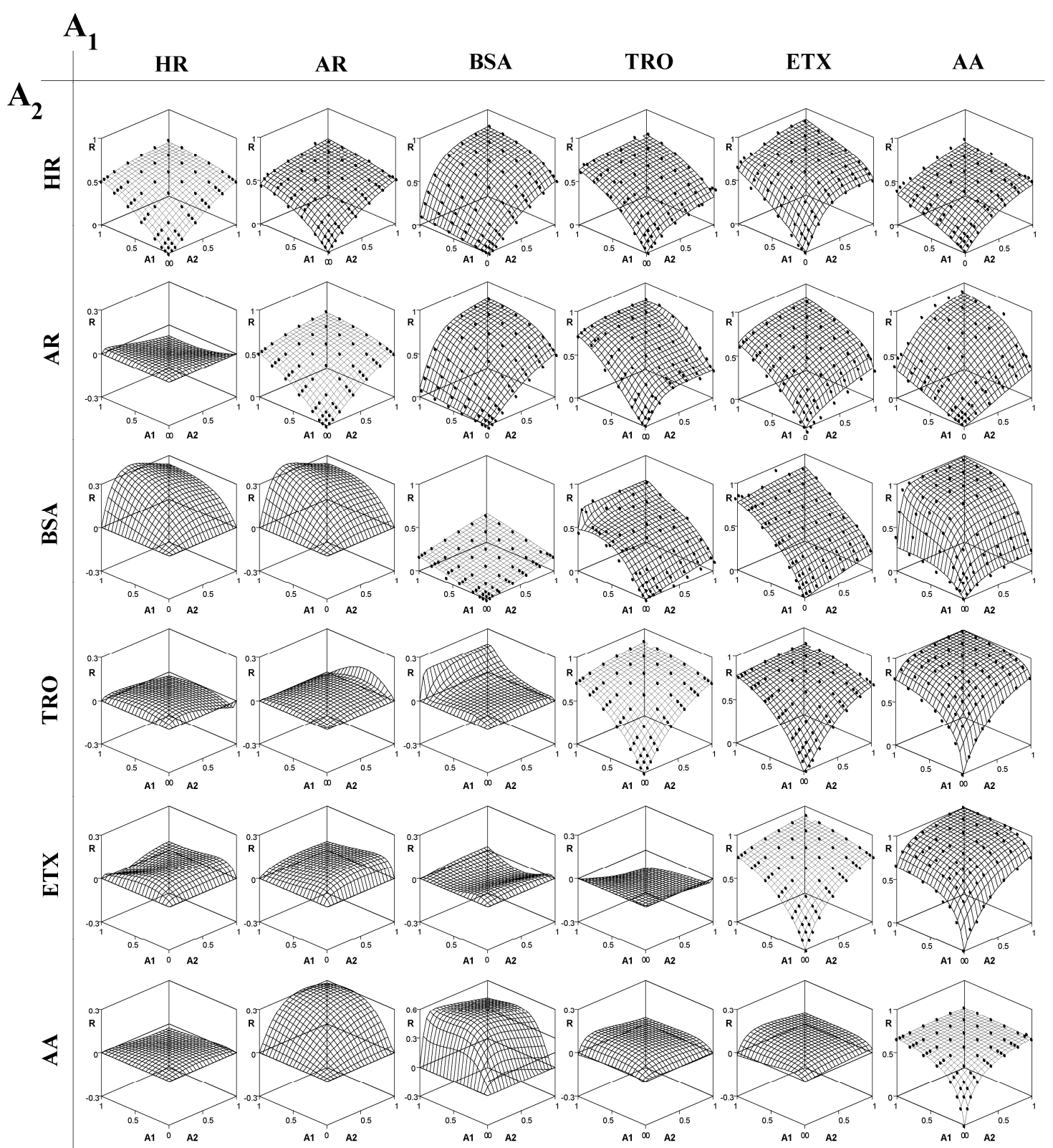

Figure 5: Matrix combination responses for the CM, which is organized as follows: a) in the diagonal it can be seem the results obtained for the controls; b) in the top part of the diagonal the surface responses for each pair antioxidant combination is presented; and c) in the bottom diagonal part the differences "scenery" between their respective null interaction form and the obtained response is presented. Numerical results are in Table A1 and Table 3. The reader should note that the resulting scenary of the case AA $v s$ BSA has different $R$ axes that all other ones. 


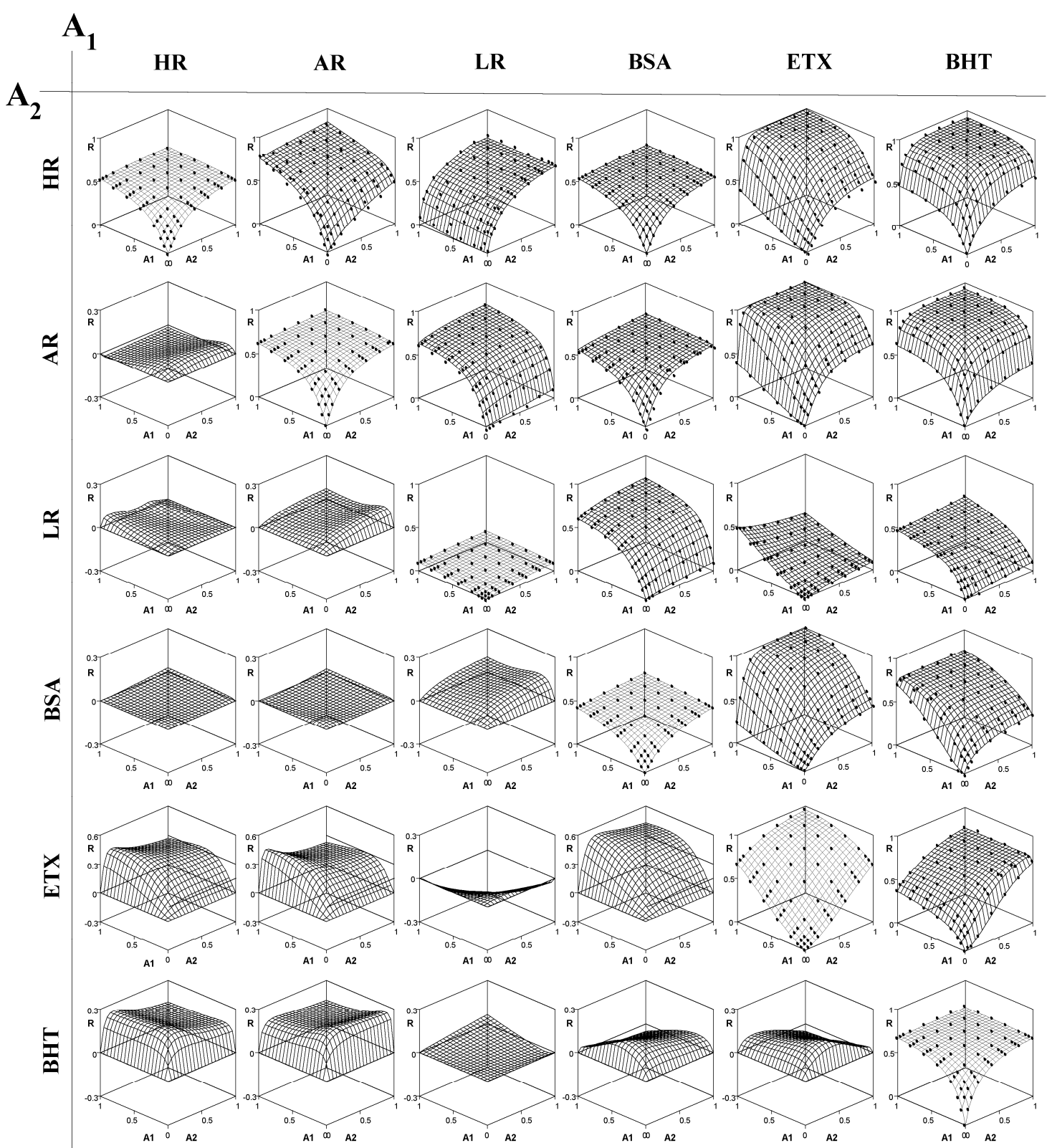

Figure 6: Matrix combination responses for the $\beta \mathrm{CM}$, which is organized as follows: a) in the diagonal it can be seem the results obtained for the controls; b) in the top part of the diagonal the surface responses for each pair antioxidant combination is presented; and c) in the bottom diagonal part the differences "scenery" between their respective null interaction form and the obtained response is presented. Numerical results in Table A2 and Table 3. The reader should note that the resulting scenary of the case ETX $v s$ RH, ETX $v s$ RA and ETX $v s$ BSA has different $R$ axes that all other ones. 
Table A1: Parametric values of the joint action of six different antioxidants in the crocin oxidation reaction. The null interaction and synergy hypotheses are compared under the independent action and addition concentration suppositions, by fitting the experimental results to the (5) and (7) generalized models. In all the presented results the parameters estimations are significant.

\section{INDEPENDENT ACTION (IA)}

\begin{tabular}{|c|c|c|c|c|c|c|c|c|c|c|c|}
\hline $\begin{array}{l}\mathbf{A}_{1} \\
\mathbf{A}_{2}\end{array}$ & & $\begin{array}{l}\text { ETX } \\
\text { TRO }\end{array}$ & $\begin{array}{c}\text { AA } \\
\text { BSA }\end{array}$ & $\begin{array}{l}\text { AA } \\
\text { RA }\end{array}$ & $\begin{array}{l}\mathrm{AA} \\
\mathrm{RH}\end{array}$ & $\begin{array}{l}\text { ETX } \\
\text { BSA }\end{array}$ & $\begin{array}{c}\text { ETX } \\
\text { RA }\end{array}$ & $\begin{array}{c}\text { ETX } \\
\text { RH }\end{array}$ & $\begin{array}{c}\text { TRO } \\
\text { RA }\end{array}$ & $\begin{array}{c}\text { AA } \\
\text { TRO }\end{array}$ & $\begin{array}{c}\text { AA } \\
\text { ETX }\end{array}$ \\
\hline \multirow{3}{*}{ response to $A_{l}$} & $K_{1}$ & 0.904 & 0.272 & 0.385 & 0.561 & 0.297 & 0.674 & 0.522 & 0.895 & 0.668 & 0.700 \\
\hline & $m_{1}$ & 0.369 & 0.185 & 0.373 & 0.408 & 0.705 & 0.868 & 0.172 & 0.528 & 0.105 & 0.139 \\
\hline & $a_{1}$ & 1.041 & 1.314 & 1.359 & 1.057 & 1.239 & 0.795 & 1.248 & 1.387 & 0.884 & 0868 \\
\hline \multirow{3}{*}{ response to $A_{2}$} & $K_{2}$ & 0.710 & 0.204 & 0.540 & 1.000 & 1.000 & 1.000 & 1.000 & 0.324 & 0.830 & 0.657 \\
\hline & $m_{2}$ & 0.380 & 0.166 & 0.601 & 1.702 & 0.427 & 0.672 & 0.751 & 0.141 & 0.153 & 0.100 \\
\hline & $a_{2}$ & 1.322 & 1.363 & 0.979 & 0.915 & 0.960 & 1.007 & 1.099 & 1.338 & 0.668 & 0.759 \\
\hline \multirow{4}{*}{$\begin{array}{r}A_{1} \text { as perturbing factor } \\
\text { for params. of the } \\
\text { response to } A_{2}\end{array}$} & $b_{k 2}$ & -0.904 & -- & -0.985 & -- & -0.784 & -- & -- & -- & - & - \\
\hline & $c_{k 2}$ & -- & -0.739 & -0.990 & -- & -- & -- & 3.111 & -0.628 & - & - \\
\hline & $b_{m 2}$ & -- & -0.655 & -- & -- & -0.724 & -- & -- & -- & - & - \\
\hline & $c_{m 2}$ & -- & -- & 2.287 & 1.147 & -- & -- & 7.465 & -- & - & - \\
\hline \multirow{4}{*}{$\begin{array}{r}A_{2} \text { as perturbing factor } \\
\text { for params. of the } \\
\text { response to } A_{1}\end{array}$} & $b_{k 1}$ & -- & -- & - & -- & -- & -- & -- & -- & - & - \\
\hline & $c_{k 1}$ & -- & -- & -- & -- & -- & -- & -- & -- & - & - \\
\hline & $b_{m l}$ & -- & 32.809 & -- & -0.792 & 1.723 & -- & 0.631 & -- & - & - \\
\hline & $c_{m l}$ & -- & 8.744 & -- & -- & -- & -- & -- & -- & 2.621 & 2.115 \\
\hline \multirow{2}{*}{ comp / coop } & $s$ & -- & -- & -- & -- & -0.648 & 7.421 & 0.393 & -0.990 & 0.980 & - \\
\hline & $\mathbf{R}_{\text {ad }}^{2}$ & 9932 & 0.9756 & 0.9854 & 0.9935 & 0.9951 & 0.9940 & 0.9967 & 0.9944 & 0.9932 & 0.9807 \\
\hline
\end{tabular}

\section{CONCENTRATION ADDITION (CA)}

\begin{tabular}{|c|c|c|c|c|c|c|c|c|c|c|c|c|}
\hline $\begin{array}{l}\mathbf{A}_{1} \\
\mathbf{A}_{2}\end{array}$ & & $\begin{array}{l}\mathrm{RH} \\
\mathrm{RH}\end{array}$ & $\begin{array}{l}\text { RA } \\
\text { RA }\end{array}$ & $\begin{array}{l}\text { BSA } \\
\text { BSA }\end{array}$ & $\begin{array}{l}\text { TRO } \\
\text { TRO }\end{array}$ & $\begin{array}{l}\text { ETX } \\
\text { ETX }\end{array}$ & $\begin{array}{l}\text { AA } \\
\text { AA }\end{array}$ & $\begin{array}{l}\text { BSA } \\
\text { RA }\end{array}$ & $\begin{array}{c}\text { BSA } \\
\text { RH }\end{array}$ & $\begin{array}{l}\text { RH } \\
\text { RA }\end{array}$ & $\begin{array}{c}\text { RH } \\
\text { TRO }\end{array}$ & $\begin{array}{l}\text { TRO } \\
\text { BSA }\end{array}$ \\
\hline \multirow{3}{*}{ joint response } & $K$ & 0.545 & 0.587 & 0.476 & 0.868 & 0.947 & 0.688 & 0.735 & 0.818 & 0.460 & 0.777 & 0.719 \\
\hline & $m$ & 0.484 & 0.516 & 1.952 & 0.437 & 0.370 & 0.129 & 3.238 & 62.253 & 0.323 & 0.465 & 1.343 \\
\hline & $a$ & 1.333 & 1.333 & 1.068 & 1.117 & 0.845 & 0.756 & 1.344 & 0.727 & 1.002 & 1.049 & 1.474 \\
\hline relative potency & $p$ & 1.016 & 1.000 & 0.949 & 1.001 & 1.000 & 1.000 & 6.017 & 5.144 & 0.993 & 1.087 & 4.957 \\
\hline \multirow{2}{*}{$\begin{array}{r}A_{1} \text { altering eff. conc. of } \\
A_{2}\end{array}$} & $b_{D 2}$ & -- & -- & -- & -- & -- & -- & -- & -- & -- & -- & -- \\
\hline & $c_{D 2}$ & -- & -- & -- & -- & 0.029 & -- & -- & -- & -- & 2.284 & -- \\
\hline \multirow{2}{*}{$\begin{array}{r}A_{2} \text { altering } \\
\text { eff. conc. of } A_{1}\end{array}$} & $b_{D I}$ & -- & -- & -- & 0.002 & -- & -0.104 & -- & -- & -0.919 & -- & -0.990 \\
\hline & $c_{D I}$ & 0.103 & 0.072 & -- & -- & -- & -- & -- & -- & 0.145 & -- & -- \\
\hline \multirow{4}{*}{$\begin{array}{r}A_{I} \text { as perturbing factor } \\
\text { for params. of the joint } \\
\text { response }\end{array}$} & $b_{k 2}$ & -- & -- & -- & -- & -- & -- & -0.097 & -- & -- & -- & -- \\
\hline & $c_{k 2}$ & -- & -- & -- & -- & -- & -- & -- & 1.667 & -- & -- & -- \\
\hline & $b_{m 2}$ & -- & -- & 0.342 & -- & -- & -- & -0.311 & 48.811 & -- & -- & -0.636 \\
\hline & $c_{m 2}$ & -- & -- & -- & -- & -- & -- & -- & -- & -- & -- & -- \\
\hline \multirow{5}{*}{$\begin{array}{r}A_{2} \text { as perturbing factor } \\
\text { for params. of the joint } \\
\text { response }\end{array}$} & $b_{k 1}$ & -- & -- & -- & -- & -- & -- & -- & -- & -- & -- & -- \\
\hline & $c_{k l}$ & -- & -- & -- & -- & -- & -- & 2.402 & -- & -- & -- & -- \\
\hline & $b_{m l}$ & -- & -- & -- & -- & -- & -- & -- & -- & -- & -- & -- \\
\hline & $c_{m l}$ & 0.109 & 0.071 & -- & -- & -- & -- & -- & -- & 0.237 & -- & -- \\
\hline & $\mathbf{R}_{\text {ad }}^{2}$ & .9939 & 0.9999 & 0.9999 & 0.9993 & 0.9995 & 0.9998 & 0.9984 & 0.9995 & 0.9996 & 0.9919 & 0.9834 \\
\hline
\end{tabular}


Table A2: Parametric values of the joint action of six different antioxidants in the crocin oxidation reaction. The null interaction and synergy hypotheses are compared under the independent action and addition concentration suppositions, by fitting the experimental results to the (5) and (7) generalized models. In all the presented results the parameters estimations are significant.

\section{INDEPENDENT ACTION (IA)}

\begin{tabular}{|c|c|c|c|c|c|c|c|c|c|c|c|}
\hline $\begin{array}{l}\mathbf{A}_{1} \\
\mathbf{A}_{2}\end{array}$ & & $\begin{array}{l}R L \\
R H\end{array}$ & $\begin{array}{l}R L \\
R A\end{array}$ & $\begin{array}{c}B S A \\
R L\end{array}$ & $\begin{array}{c}E T X \\
R H\end{array}$ & $\begin{array}{c}E T X \\
R A\end{array}$ & $\begin{array}{l}E T X \\
B S A\end{array}$ & $\begin{array}{c}B H T \\
R H\end{array}$ & $\begin{array}{c}B H T \\
R A\end{array}$ & $\begin{array}{l}B H T \\
B S A\end{array}$ & $\begin{array}{l}B H T \\
E T X\end{array}$ \\
\hline \multirow{3}{*}{ response to $A_{l}$} & $K_{1}$ & 0.711 & 0.603 & 0.627 & 0.547 & 0.618 & 0.440 & 0.637 & 0.614 & 0.829 & 1.000 \\
\hline & $m_{1}$ & 2.187 & 4.110 & 0.200 & 0.219 & 0.171 & 0.261 & 0.239 & 0.167 & 0.531 & 0.454 \\
\hline & $a_{1}$ & 2.591 & 0.908 & 0.953 & 1.075 & 1.072 & 1.096 & 0.885 & 1.012 & 1.559 & 1.154 \\
\hline \multirow{3}{*}{ response to $A_{2}$} & $K_{2}$ & 0.732 & 0.646 & 0.166 & 1.000 & 0.876 & 0.996 & 0.471 & 0.460 & 0.448 & 0.466 \\
\hline & $m_{2}$ & 0.184 & 0.146 & 0.728 & 1.225 & 1.111 & 1.981 & 0.167 & 0.239 & 0.273 & 1.218 \\
\hline & $a_{2}$ & 0.782 & 0.918 & 0.987 & 1.474 & 1.418 & 1.410 & 0.943 & 0.779 & 0.677 & 0.784 \\
\hline \multirow{4}{*}{$\begin{array}{r}A_{1} \text { as perturbing factor } \\
\text { for params. of the } \\
\text { response to } A_{2}\end{array}$} & $b_{k 2}$ & -0.199 & -- & 1.230 & -- & -- & -0.147 & -- & 41.121 & -- & -- \\
\hline & $c_{k 2}$ & -- & 0.274 & -- & 0.240 & -- & -- & -- & 22.524 & -0.365 & 0.903 \\
\hline & $b_{m 2}$ & -- & 0.648 & -0.564 & -- & -- & -- & -- & 5.653 & -0.678 & -- \\
\hline & $c_{m 2}$ & 0.934 & 2.422 & -- & 5.475 & 6.988 & 6.776 & -- & 32.123 & 12.196 & 21.258 \\
\hline \multirow{4}{*}{$\begin{array}{r}A_{2} \text { as perturbing factor } \\
\text { for params. of the } \\
\text { response to } A_{l}\end{array}$} & $b_{k I}$ & -- & -- & -- & -- & -- & -- & -- & -- & -- & -- \\
\hline & $c_{k l}$ & -- & -- & -- & -- & -- & -- & -- & -- & -- & -- \\
\hline & $b_{m l}$ & -- & -- & -- & 0.721 & 0.578 & 1.070 & 20.734 & -- & -- & -- \\
\hline & $c_{m l}$ & -- & -- & -- & -- & -- & -- & 15.155 & -- & -- & -- \\
\hline \multirow[t]{2}{*}{ comp / coop } & $s$ & -0.990 & -- & 1.245 & -- & -0.223 & -- & 5.653 & -- & -- & 0.143 \\
\hline & $\mathbf{R}_{\text {ad }}^{2}$ & 9932 & 0.9920 & 0.9996 & 0.9998 & 0.9997 & 0.9995 & 0.9998 & 0.9995 & 0.9994 & 0.9968 \\
\hline
\end{tabular}

\section{CONCENTRATION ADDITION (CA)}

\begin{tabular}{rrrrrrrrrrrrrr}
\hline $\mathbf{A}_{1}$ & & $R H$ & $R A$ & $R L$ & $B S A$ & $E T X$ & $B H T$ & $R A$ & $B S A$ & $B S A$ & $E T X$ & $B H T$ \\
$\mathbf{A}_{2}$ & & $R H$ & $R A$ & $R L$ & $B S A$ & $E T X$ & $B H T$ & $R H$ & $R H$ & $R A$ & $R L$ & $R L$ \\
\hline & $K$ & 0.608 & 0.706 & 0.153 & 0.407 & 0.919 & 0.693 & 0.593 & 0.654 & 0.695 & 1.000 & 0.392 \\
joint response & $m$ & 0.212 & 0.166 & 0.648 & 0.233 & 1.051 & 0.140 & 0.162 & 0.200 & 0.225 & 1.918 & 0.127 \\
& $a$ & 1.088 & 1.067 & 0.939 & 1.008 & 1.247 & 0.805 & 0.963 & 1.080 & 1.129 & 1.257 & 0.953 \\
\hline relative potency & $p$ & 1.005 & 0.976 & 1.013 & 0.979 & 1.073 & 1.005 & 0.341 & 0.900 & 1.435 & 1.360 & 0.075 \\
\hline$A_{1}$ altering eff. conc. of & $b_{D 2}$ & -- & -- & -- & -- & -- & -- & -- & -- & -- & -- & -- \\
$A_{2}$ & $c_{D 2}$ & -- & -- & -- & -- & -- & 0.075 & 1.121 & -- & -- & -- & -- \\
\hline$A_{2}$ altering & $b_{D 1}$ & -0.263 & -- & -- & -- & -- & -- & -- & -- & -0.511 & 0.322 & -- \\
eff. conc. of $A_{1}$ & $c_{D 1}$ & -- & -- & -- & -- & -- & -- & -- & -- & -- & -- & 0.175 \\
\hline \multirow{2}{*}{$\begin{array}{l}* \\
A_{1} \text { as perturbing factor }\end{array}$} & $b_{k 2}$ & -- & -- & -- & -0.086 & -- & -- & -0.090 & -- & -- & -- & -- \\
for params. of the joint & $c_{k 2}$ & 0.752 & 1.070 & -- & -- & -0.383 & -- & -- & 0.982 & 1.335 & -- & 0.679 \\
response & $b_{m 2}$ & -- & -- & -- & -- & -- & -- & -- & -- & -- & 0.376 & -- \\
& $c_{m 2}$ & -- & -- & -- & -- & -- & -- & -- & -- & -- & -- & -- \\
\hline \multirow{2}{*}{$A_{2}$ as perturbing factor } & $b_{k 1}$ & -- & -- & -- & -- & -- & -- & -- & -- & -- & -- & -- \\
for params. of the joint & $c_{k 1}$ & -- & -- & -- & -- & -- & -- & -- & -- & -- & -- & -- \\
response & $b_{m 1}$ & -- & -0.495 & -- & -- & -- & -- & -- & -0.407 & -- & -- & -- \\
& $c_{m 1}$ & -- & -- & 0.008 & 0.108 & -- & -- & 0.303 & -- & -- & -- & -- \\
\hline
\end{tabular}




\section{AQUEOUS RESIDUE}

C1: Arabica from Australia

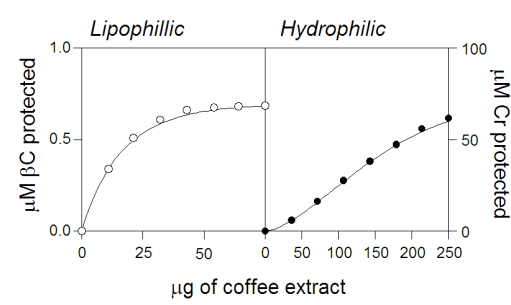

C2: Arabica from Nicaragua

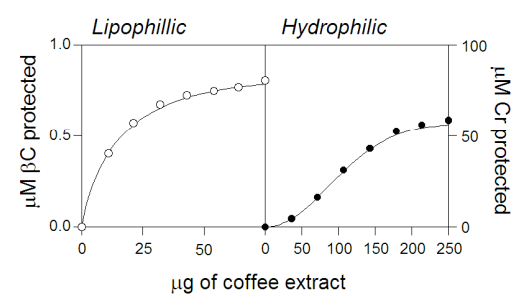

C3: Robusta from Cameroon

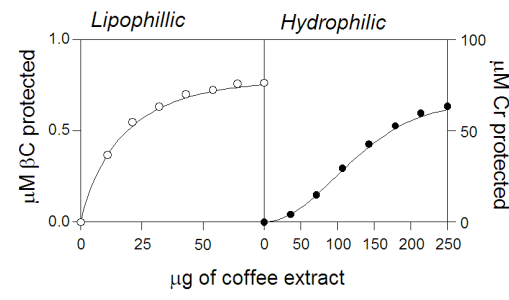

C4: Arabica from Guatemala

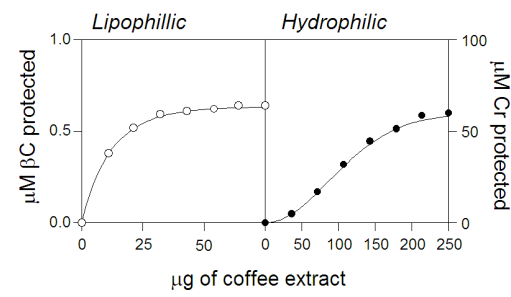

C5: Robusta from Vietnam

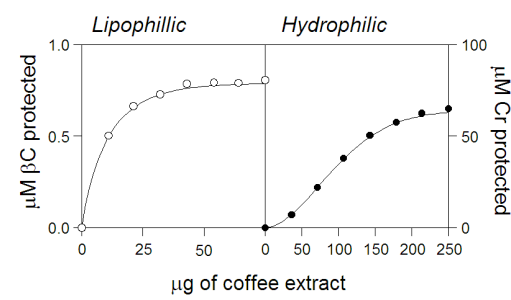

HYDROPHILIC RESIDUE

C1: Arabica from Australia

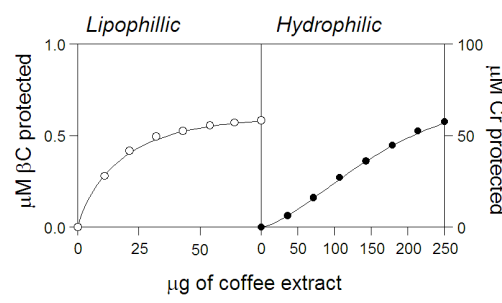

C2: Arabica from Nicaragua

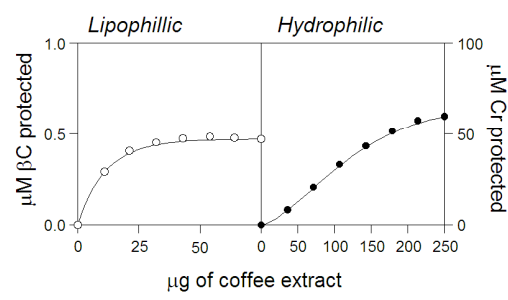

C3: Robusta from Cameroon

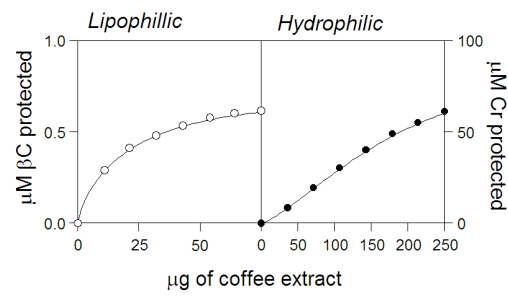

C4: Arabica from Guatemala

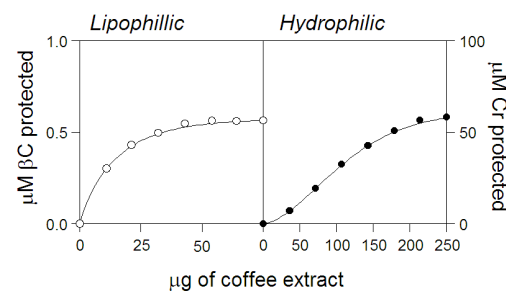

C5: Robusta from Vietnam

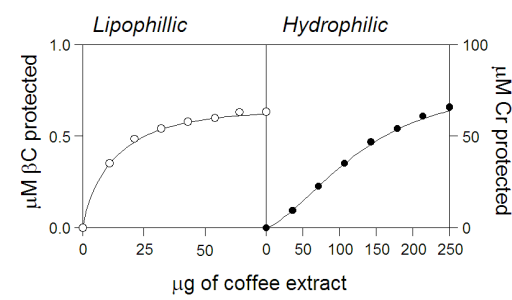

LIPOPHILIC RESIDUE

C1: Arabica from Australia

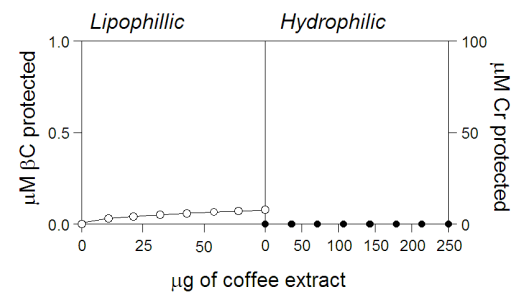

C2: Arabica from Nicaragua

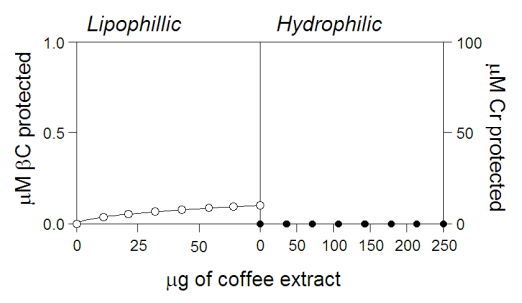

\section{C3: Robusta from Cameroon}

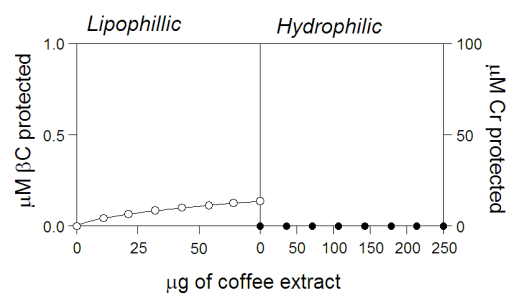

C4: Arabica from Guatemala

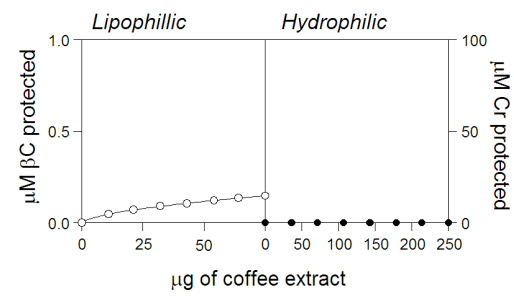

C5: Robusta from Vietnam

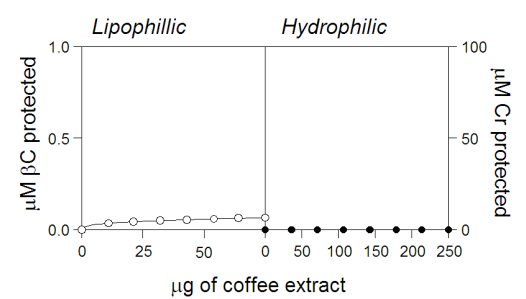

Figure A1: Antioxidant activity of coffee extracts (aqueous, hydrophilic and lipohilic residue) in both crocin and $\beta$-carotene bleaching reactions (lipophilic and hydrophilic media respectively); Cotrol series (๑) and seven dilutions ( $\bigcirc: 1 / 7, \boldsymbol{\Delta}: 2 / 7, \triangle: 3 / 7, \mathbf{\square}: 4 / 7, \square: 5 / 7$, : 6/7, $\diamond: 7 / 7)$ were included in each case. The concentrations range tested for all extracts are $0-(0.1)-0.7 \mathrm{~g} / \mathrm{L}$ in final solution of the reaction. No results were found when the liphophilic residue was tested in the hydrophilic reaction (CBA). 


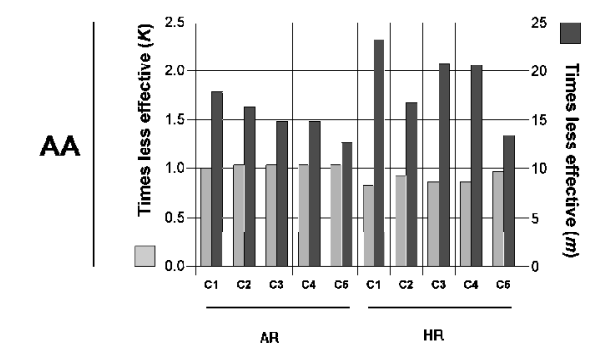

BHA
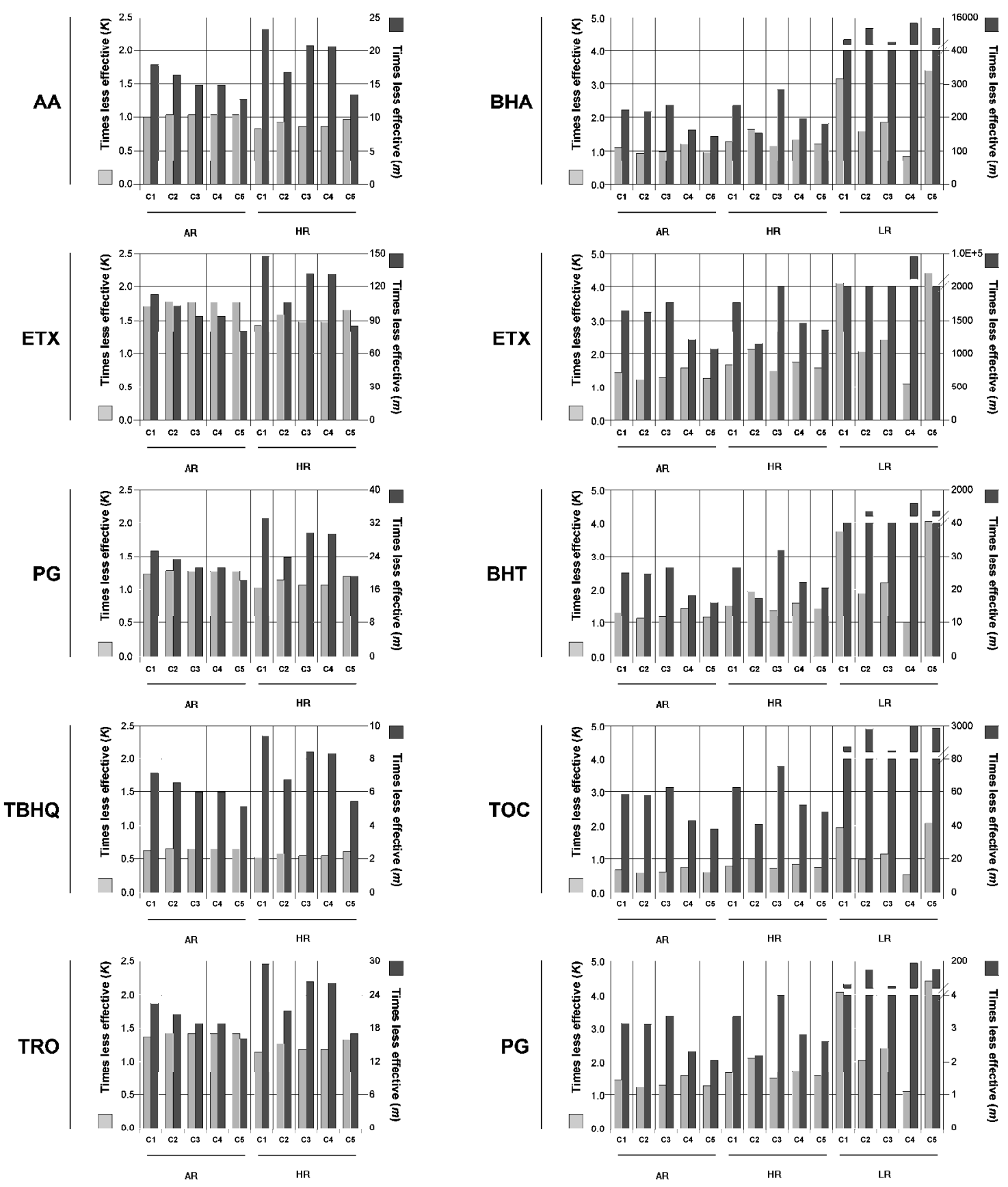

Figure A2: Specific potencial equivalence of each the fractionated residues (RA, RH and RL) of all coffee samples tested (C1-C5) against five common commerical antioxidants for each of the $\mathrm{H}$ and $\mathrm{L}$ reactions, the CM (AA, ETX, PG, TBHQ and TRO) and the $\beta \mathrm{CM}$ (BHA, ETX, BHT, TOC and PG). The equivalence is computed in terms of the numerical parameters $K$ and $m$ of Eq. 2. Each independent graph belongs to the computed equivalence referred to the commercial antioxidant indicated on the left side. All graphs display the times less effective that the coffee samples are regarding the commerical antioxidant by the two different but complementary parameter values of Eq. 2. The left axis computes the times less effective of all coffee samples in terms of its maximum protective capabilities (parameter $K$ in $\mu \mathrm{M} \bar{P}$ by the commerical antioxidant $/ \mu \mathrm{M} \bar{P}$ by the respective coffee sample), while the right axis computes the times less effective of all coffee samples in terms of concentrations needed to achieve the $50 \%$ of the maximum protective effect (parameter $m$ in $\mu \mathrm{g}$ commerical antioxidant $/ \mu \mathrm{g}$ respective coffee sample). Readers should note the break of the right axis. 